Hendrik Poorter · Cynthia P. E. van Rijn

Tytti K. Vanhala $\cdot$ Koen J. F. Verhoeven

Yvonne E. M. de Jong · Piet Stam · Hans Lambers

\title{
A genetic analysis of relative growth rate and underlying components in Hordeum spontaneum
}

Received: 6 March 2004 / Accepted: 4 August 2004 / Published online: 20 November 2004

(C) Springer-Verlag 2004

\begin{abstract}
Species from productive and unproductive habitats differ inherently in their relative growth rate (RGR) and a wide range of correlated quantitative traits. We investigated the genetic basis of this trait complex, and specifically assessed whether it is under the control of just one or a few genes that can act as 'master switches" by simultaneously affecting a range of traits in the complex. To address this problem, we crossed two Hordeum spontaneum lines originating from two habitats that differ in productivity. The $F_{3}$ offspring, in which parental alleles are present in different combinations due to recombination and segregation, was analysed for RGR and its underlying components (leaf area ratio, unit leaf rate, photosynthesis, respiration), as well as a number of other physiological and morphological parameters. For this intra-specific comparison, we found a complex of positively and negatively correlated traits, which was quite similar to what is generally observed across species. A quantitative trait loci (QTL) analysis
\end{abstract}

Electronic Supplementary Material Supplementary material is available for this article at http://dx.doi.org/10.1007/s00442-004$1705-1$

H. Poorter $(\bowtie) \cdot$ C. P. E. van Rijn · Y. E. M. de Jong

H. Lambers

Plant Ecophysiology, Utrecht University,

PO Box 800.84, 3508 TB Utrecht, The Netherlands

E-mail: H.Poorter@bio.uu.nl

Tel.: + 31-30-2536859

Fax: $+31-30-2518366$

T. K. Vanhala · P. Stam

Laboratory of Plant Breeding, Department of Plant Sciences,

Wageningen University, PO Box 386,

6700 AJ Wageningen, The Netherlands

K. J. F. Verhoeven

Department of Plant Population Biology,

Netherlands Institute of Ecology, NIOO-KNAW,

PO Box 40, 6666 ZG Heteren, The Netherlands

H. Lambers

School of Plant Biology, Faculty of Natural and

Agricultural Sciences, The University of Western Australia,

Crawley, WA, 6009, Australia showed three major and one minor QTL for RGR. Most other variables of the growth-trait complex showed fewer QTLs that were typically scattered over various locations on the genome. Thus, at least in $H$. spontane$u m$, we found no evidence for regulation of the trait complex by one or two master switches.

Keywords Specific leaf area - Unit leaf rate

Quantitative trait loci $\cdot$ Trait complex $\cdot$ Photosynthesis

\section{Introduction}

Plant species differ considerably in the relative growth rate (RGR, net rate of increase in biomass per unit biomass already present) they can achieve under favourable conditions. This is an intriguing phenomenon, especially as plant species that normally occur in fertile habitats often show faster maximum growth rates under favourable growth conditions than plants from nutrient-poor environments (Grime and Hunt 1975; Poorter and Remkes 1990). With the difference in RGR come differences in a wide variety of parameters related to physiology, morphology and chemical composition which together form a cluster of correlated traits (Grime 1979; Lambers and Poorter 1992; Chapin et al. 1993; Wright et al. 2004). Species that show fast growth generally have an inherently high specific leaf area (SLA; leaf area:leaf mass), a higher leaf mass fraction (LMF; leaf mass:plant mass), a fast rate of photosynthesis per unit leaf mass and respiration per unit leaf and root mass, a higher rate of ion uptake per unit root mass, as well as higher concentrations of $\mathrm{N}$ and minerals. Inherently slow-growing species generally show a higher biomass allocation to roots, higher concentrations of $\mathrm{C}$ in their organs, at least partly caused by higher concentrations of compounds such as structural carbohydrates and lignin, more biomass per organ volume and higher leaf longevity (Lambers and Poorter 1992; Reich et al. 1997; Poorter and Garnier 1999). 
The above-mentioned traits are quantitative by nature, and generally under polygenic control (Tanksley 1993; Prioul et al. 1997). An interesting question is how such a trait complex, as found in broad interspecific comparisons across several genera, has evolved. Independent selection on the different traits could have recurrently brought together the appropriate set of genes that involved a large number of small adaptations. Alternatively, all the traits could have been affected simultaneously by one or a few regulatory genes with a wide range of pleiotropic effects. Such a regulatory gene could control the production of an important hormone, which subsequently activates or deactivates a range of genes. Gibberellic acid, for example, is known to destabilise a class of proteins that normally inhibits transcription of different genes related to growth (Thomas and Sun 2004). Another potential way in which a regulatory gene may act is to produce a specific transcription factor that determines the functioning of different other genes at the same time (Maleck et al. 2001). In all cases, such a 'master switch' affects transcription and/or translation of a wide range of genes. Master switches have been proposed in plants, e.g. for resistance against cold (Jaglo-Ottosen et al. 1998) and pathogens (Spoel et al. 2003). Partly on the basis of strong convergence of the phenotypes of inherently slow-growing species and of stressed plants in general, partly based on the observation that point mutations in hormone production affect multiple traits simultaneously, Chapin et al. (1993) suggested that such a master switch could well determine the slow- versus fast-growth trait complex.

Until the beginning of the 1990s, the genetic background of quantitative traits could only be glimpsed at with extensive crossing studies, which enabled estimates of broad sense heritability, and genetic correlations between different traits, as well as the number of genes that were involved. With the advent of quantitative trait loci (QTL) analysis, it has become possible to identify chromosome regions responsible for quantitative trait variation, by exploring correlations in a segregating population between trait variation and genetic markers that are dispersed over the entire genome (Lander and Botstein 1989). Revealing the genetic basis of the traits that are associated in the growth-rate complex can provide an elegant test of whether the fast- and slowgrowth complex is controlled by one or a few pleiotropic genes, that may act as master switches and can convert the entire trait complex from one state (fast-growth) into the other (slow-growth). Up to now, the QTL basis for growth rate has mainly been studied for simple size-related parameters, such as plant height, leaf length and shoot biomass (Causse et al. 1995; Mian et al. 1998; Wu 1998; Prioul et al. 1999), or at best investigated for some growth-related parameters such as SLA and photosynthesis (Yin et al. 1999; Hervé et al. 2001). Recently, El-Lithy et al. (2004) analysed RGR variation in Arabidopsis, based on leaf area and shoot biomass. However, the genetic architecture of the growth process itself, in the framework of a whole-plant perspective on RGR and related traits [unit leaf rate (ULR), SLA, LMF, photosynthesis, respiration], has not yet been examined.

We studied RGR and its underlying parameters in a segregating population derived from an intra-specific cross between two plants from contrasting populations of wild barley, Hordeum spontaneum. This species is the progenitor of cultivated barley, and occurs in a wide range of environments across the fertile crescent (Nevo et al. 1979). It is a naturally selfing, diploid grass with generally low levels of outcrossing (Brown et al. 1978). Large genetic variation has been found between these populations with regard to isozyme polymorphisms, RFLPs and RAPD-markers which correlates with the occurrence of these populations in specific environments (Nevo 1992). There is also phenotypic variation at the level of growth, physiology and morphology, such as RGR, rate of photosynthesis, drought and salt tolerance, and response to N-starvation (Nevo et al. 1984; Ellis et al. 2000; Ivandic et al. 2000; Robinson et al. 2000; Van Rijn et al. 2000). Crossing two plants from contrasting habitats creates random re-arrangements of parental alleles in the genome, due both to meiosis and recombination. From the $\mathrm{F}_{2}$ population a dense AFLPmarker map was constructed. The $F_{3}$ population was measured for a range of traits related to RGR and the underlying carbon and nitrogen economy. First, we determined broad-sense heritability and assessed to what extent the offspring has a more extreme phenotype than both parents (transgressive segregation). Second, we investigated whether phenotypic traits across $F_{3}$ lines still form trait complexes that correlate with those observed across species. Third, we used a QTL analysis to gain insight into the genetic structure with respect to the investigated traits. Finally, we evaluated indications for possible master switches related to the growth trait complex.

\section{Materials and methods}

\section{Plant material and growth}

An $F_{2}$ mapping population was derived from a cross between two $H$. spontaneum $\mathrm{C}$. Koch populations, originating from two locations in Israel: Ashqelon and Mehola. The Ashqelon parent comes from a coastal site, and the Mehola parent was collected in the Jordan Valley, which is a more steppic, marginal Mediterranean habitat. Both sites have low rainfall, but soil nutrient availability and productivity was found to be higher at the Mehola site (Verhoeven et al. 2004). More details on the parents are given in Van Rijn et al. (2000). To obtain a mapping population, eight $F_{1}$ plants were selfed to obtain eight $F_{2}$ subfamilies. To prevent outcrossing, all spikes were enclosed in paper bags at anthesis. A total of $233 \mathrm{~F}_{2}$ plants were grown and used as a mapping population, of which $140 \mathrm{~F}_{3}$ lines were used for the subsequent analysis of growthrelated traits. 
Growth procedures followed Van Rijn et al. (2000). In short, after germination on moistened filter paper, seedlings were transferred to sand saturated with nutrient solution and placed in a growth chamber under the following conditions: $14 / 10 \mathrm{~h}$ day/night, $20^{\circ} \mathrm{C}$ day/night, irradiance of $450 \pm 25 \mu \mathrm{mol} \mathrm{m} \mathrm{m}^{-2}$, relative humidity $70 \%$. Seven days after germination, seedlings were placed in tanks containing a continuously aerated full nutrient solution (with an $\mathrm{NO}_{3}{ }^{-}$concentration of 2 $\mathrm{mM}$ ). Plants were rotated within the growth room every other day. No mutual shading occurred and all plants remained vegetative, showing no dead leaves during the experiment.

\section{Linkage map}

Full details on markers and the construction of the genetic map are given in the Appendix. $H$. spontaneum has seven chromosomes and will have a genome size close to that of H. vulgare (ca. 1,000 cM; Ramsay et al. 2000). Seven linkage groups could be assigned unambiguously to the different chromosomes, two were tentatively assigned and two small fragments remained unassigned. An unexpected level of heterozygosity in one of the parents made it impossible to map the entire genome. For that reason, the total length of the linkage map is $445 \mathrm{cM}$, which implies that only half of the total genome length is covered by our map. Consequently, our analysis is expected to miss out on a number of true QTLs. However, the part that is present is reliable and appropriate for further linkage and QTL mapping.

\section{Experimental design}

The growth experiment was carried out on a sample of $140 \mathrm{~F}_{3}$ lines. To spread the workload, plants were grown in five blocks, separated in time. Each block consisted of five sets, that were grown 1 week apart. Each set comprised one individual from 28 lines plus the two parental lines as controls. Thus, after 5 weeks one individual from each of the 140 lines was measured, and when all blocks were completed we had obtained five independent replicates per line. Whole plant fresh mass was measured for each of the five individuals (after blotting the roots gently with tissue paper) 14 days after germination, after which plants were returned to the nutrient solution. Data from a pilot experiment showed that blotting had no measurable effect on the RGR of the plants. At day 21, 7 days after the non-destructive measurement, leaf photosynthesis was determined for some plants, whereas root respiration and leaf thickness were measured for the others. The scheme for these measurements was such that at the end of the experiment we had obtained photosynthesis data for three individuals of each line and respiration data for the two others. After these measurements, all plants were harvested as specified in the next paragraph.

\section{Measurements}

\section{Physiological traits}

Gas exchange parameters were determined on an area of approximately $7 \mathrm{~cm}^{2}$ in the middle part of the youngest fully expanded leaf on the main tiller, using an infra-red gas analyser (LI-6262, LICOR, Lincoln, Ne., USA) in the differential mode in an open system. After acclimation for 30-45 min, $\mathrm{CO}_{2}$ and $\mathrm{H}_{2} \mathrm{O}$ exchange was measured. The conditions in the cuvette were similar to those in the growth room, i.e. $35 \mathrm{~Pa} \mathrm{CO}_{2}$, leaf temperature $20^{\circ} \mathrm{C}$ and a PPFD of $450 \mu \mathrm{mol} \mathrm{m} \mathrm{m}^{-2} \mathrm{~s}^{-1}$. Thereafter, gas exchange was determined at a PPFD of $1,500 \mu \mathrm{mol} \mathrm{m} \mathrm{m}^{-2}$ $\mathrm{s}^{-1}$ to assess photosynthesis at light saturation. Finally, plants were placed in the dark for $20 \mathrm{~min}$ and dark respiration was measured. Root respiration was determined on detached roots as the decrease of $\mathrm{O}_{2}$ concentration in an airtight cuvette containing a nutrient solution, using a Clark-type electrode (Yellow Springs Instruments, Ohio, USA).

To determine the concentration of $\mathrm{C}$, organic $\mathrm{N}$ and $\mathrm{NO}_{3}{ }^{-}$, the three youngest fully expanded leaves of each line used in photosynthesis measurements were combined to form one sample, which was determined in duplicate. The $\mathrm{C}$ and $\mathrm{N}$ concentration of the samples were quantified using an elemental analyser (Carlo Erba 1110, Italy). Nitrate was determined according to Cataldo et al. (1975). Nitrate concentration was then subtracted from total $\mathrm{N}$ to determine the organic $\mathrm{N}$ concentration.

\section{Morphological traits}

Before the start of the experiment, the mass of each airdried seed (coated caryopsis) was determined. The youngest fully expanded leaf of the 21-day-old plant was used to determine the leaf angle between the horizontal plane and the middle part of the leaf. Leaf length was determined, on the same leaf, as the distance between the ligule and the top. Plant (shoot) height was measured as the distance between the base and the highest point of the shoot. Leaf width was measured as the average of five points in the middle of the youngest fully expanded leaf. Leaf thickness was assessed microscopically on fresh cross sections in the middle of the youngest fully expanded leaf. Measurements were made at five points: on the main vein, on the fourth vein on each side of the main vein and between the fourth and the fifth vein on both sides of the main vein: thereafter, all data were averaged. Maximum root length was determined as the distance between the base and the lowest point of the roots.

\section{Growth analysis-related traits}

Total leaf area at day 21 after germination was determined for all plants using an Li-3100 area meter 
(Li-Cor). Fresh mass of the leaves (leaf blades), stems (leaf sheaths) and roots were determined directly after the leaf area measurement, and dry mass after drying the plant material at $70^{\circ} \mathrm{C}$ for $48 \mathrm{~h}$. The leaf area ratio (LAR, leaf area per total plant mass), SLA, LMF, stem mass fraction (SMF, stem mass per total plant dry mass) and root mass fraction (RMF, root mass per total plant dry mass) were derived from the dry mass data (see Table 1 for a complete list of abbreviations of measured traits).

\section{Calculations and statistical analysis}

RGR was calculated from the total fresh mass on days 14 and 21 according to Evans (1972). Mathematically, RGR is the product of the ULR (the rate of increase in biomass per unit leaf area) and LAR. ULR was estimated by dividing RGR over the day 14-21 period by the LAR measured at day 21 , under the assumption that LAR was constant during this period. This is not nec- essarily completely correct, as some ontogenetic drift will occur (Poorter and Pothmann 1992). However, changes over a week are rather small and the workload would have been excessive if we had had to harvest an additional 700 plants on day 14 .

In the absence of strong exudation or disappearance of plant parts, ULR is determined mainly by the daily rate of photosynthesis per unit leaf area, the fraction of the daily fixed $\mathrm{C}$ that is invested in growth (FCI, thus excluding respiration and other $\mathrm{C}$ losses) and the carbon content of the newly formed plant material (Poorter 2002). An estimate of these components (necessarily rough) was made as follows: daily $\mathrm{C}$ gain of the leaves by assuming the photosynthesis per unit leaf area was constant over the day and similar for all leaves; the FCI by subtracting whole plant respiration, assuming the leaf respiration rate of all leaves to be equal, respiration of the stem during the night to be similar to that of leaf respiration per unit mass, and a respiratory quotient of root respiration of 1.2 ; the $\mathrm{C}$ content of the whole plant by assuming it to be equal to that of the leaves. LAR can

Table 1 Abbrevations of all the phenotypic traits measured, units, and the mean values of the Ashqelon and Mehola parent measured on 15 individuals each grown spaced throughout the experiment. All mass-based values are on a dry mass basis and pertain to whole plants, unless indicated otherwise

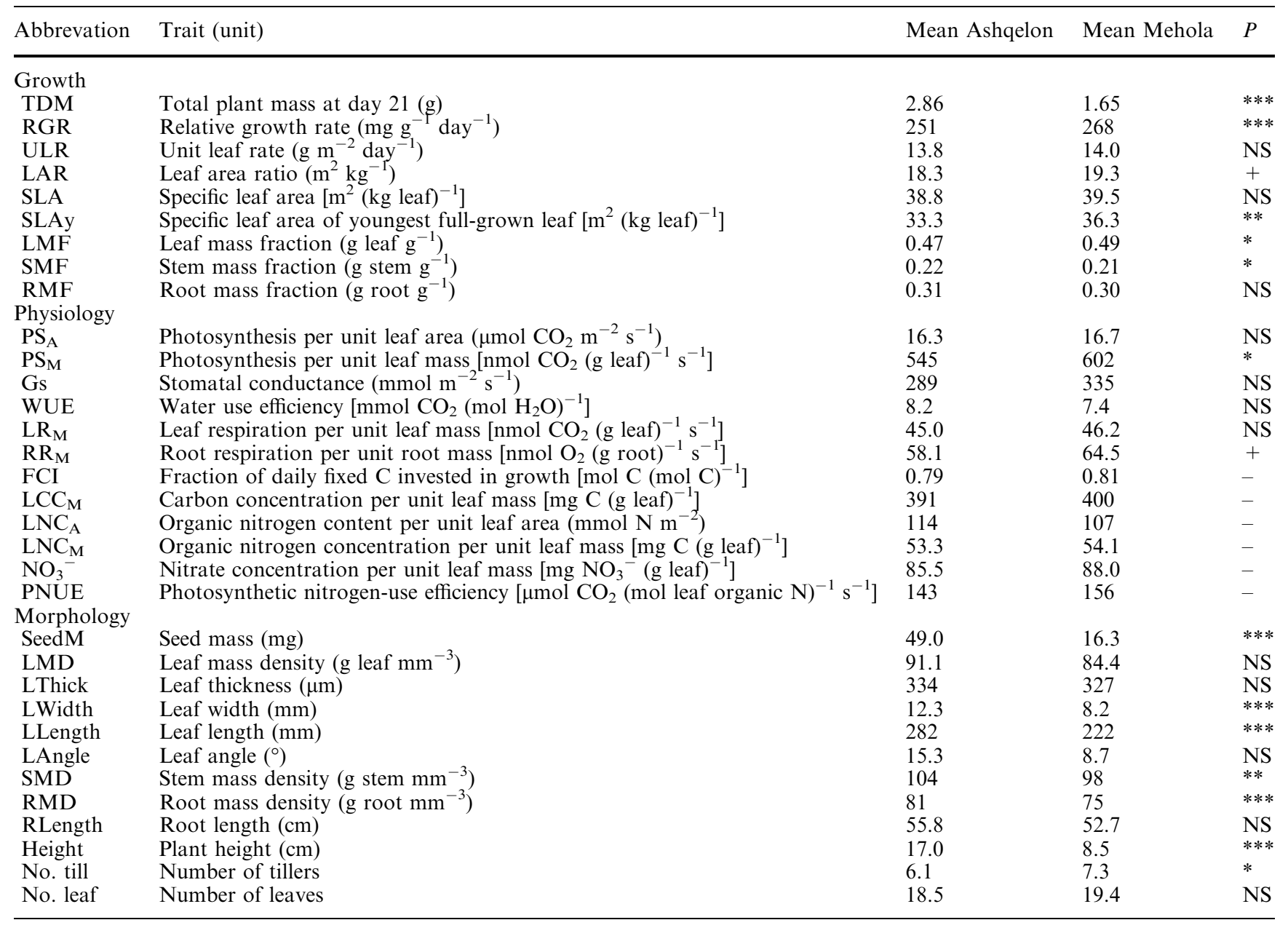

NS Non-significant; $+0.05<P<0.10 ; * P<0.05 ; * * P<0.01 ; * * * P<0.001$ 
be factored into the SLA and the LMF. Water-use efficiency (WUE) and photosynthetic nitrogen-use efficiency (PNUE) were calculated as the area-based rate of photosynthesis under ambient conditions divided by the transpiration and the organic nitrogen content per unit leaf area, respectively.

Differences between the $140 \mathrm{~F}_{3}$-lines, as well as the broad-sense heritability (fraction of the total variation ascribed to lines) were calculated using the one-way ANOVA in SPSS for Windows (release 10; SPSS Inc, Chicago, IL, USA). For the QTL analysis we used a core map with the 96 most informative markers, preferably those that had been scored co-dominantly, and at about 4-cM intervals where possible. Phenotypic data of the $\mathrm{F}_{3}$ lines were regressed on the marker genotypes of the parental $F_{2}$ plants. MapQTL version 4.0 (Van Ooijen and Maliepaard 1996) was used for interval mapping and restricted multiple QTL mapping (MQM mapping; Jansen and Stam 1994). Markers at likelihood of odds (LOD) peaks higher than 1.5 after interval mapping were tested as co-factors for inclusion in the subsequent MQM mapping. When LOD values for markers in other regions exceeded a value of 2.0 , they were added as cofactors, until the LOD profile stabilised. Finally, a restricted MQM mapping analysis was carried out, in which all co-factors were used except those that were on the linkage group that a QTL was fitted on (Van Ooijen and Maliepaard 1996). Permutation tests showed that, for this map, a genome-wide rate of false-positives of $5 \%$ corresponds to a LOD threshold of approximately 3.1. One has to be aware that the number of $F_{3}$ lines used here is relatively modest, implying that the power to detect QTLs of a given effect may not be optimal. As our aim in this experiment was not to clone a gene at a specific location, but to analyse the whole genetic constellation, we did not want to miss less significant QTLs too easily by a very strict control of the type 1 errors. Therefore, we decided to consider a second group of QTLs, with a LOD score between 2.5 and 3.1 which we denoted 'sub-significant'. The additive effect and the percentage of the total phenotypic variation explained by each putative QTL were also estimated using the MapQTL software.

\section{Results and discussion}

Phenotypic data of the parents

Table 1 shows all of the observed variables, for ease of reference categorised into three groups: traits related to growth (total dry mass and growth parameters), physiology (photosynthesis, respiration, $\mathrm{N}$ concentration) and morphology. Averaged over all blocks, plants of the Ashqelon parent had leaves that were larger and especially wider. The leaves were also somewhat more erect and, consequently, plant height was double that of the Mehola plants. Ashqelon plants started with a threetimes larger seed mass. Mehola plants, on the other hand, had a 7\% higher RGR (Table 1). This is a rather small difference compared to the $200-300 \%$ difference in maximum RGR generally found in interspecific comparisons between herbaceous species (Grime and Hunt 1975; Poorter and Remkes 1990; Van der Werf et al. 1998), but has been consistently found now for these parents in a number of experiments under different conditions (Van Rijn et al. 2000; Van Rijn 2001; Elberse 2002). The much smaller differences in RGR and growth components that are generally found in intraspecific comparisons imply that genetic analysis of the trait complex related to RGR can only be studied at a finer scale, with a necessarily larger component of uncertainty due to experimental error.

Verhoeven et al. (2004) determined total productivity of the vegetation at the two habitats where the parents were originally collected. Notwithstanding a lower precipitation, productivity at the Mehola site was three times higher than at the Ashqelon site, most likely because of a higher nutrient availability and better water retention. Thus, the differences in RGR and habitat productivity are in line with the observed correlation between RGR and habitat productivity across a wide range of plant species (Grime and Hunt 1975; Poorter and Garnier 1999).

\section{Phenotypic data of the $\mathrm{F}_{3}$ lines}

For almost all variables, the range covered by the $140 \mathrm{~F}_{3}$ lines exceeded the range covered by the parents, with the exception of seed mass, final biomass and leaf width (Table 2). Such frequent transgressive segregation can indicate that the parental genotypes typically possess a mixture of both positive and negative alleles for a given trait, resulting in some recombinant progeny lines having more extreme combinations of alleles than either parent.

Broad-sense heritability, the fraction of the variance in the full data set of $700 \mathrm{~F}_{3}$ plants attributable to variation between lines, ranged from ca. 0.15 to 0.35 for growth parameter values (Table 2). Notwithstanding the larger range in line means in the physiological parameters, heritabilities were lower. The largest heritabilities were found for morphological parameters, with values exceeding 0.4 for seed mass and leaf width. These values are relatively modest, as compared to values for growth parameters published earlier (Biere 1996; Mian et al. 1998), but indicate a solid genetic basis for possible selection for traits or trait complexes in the field.

\section{Trait correlations}

The RGR can be factored into two components: the growth rate per unit leaf area (ULR), and the leaf area per unit plant biomass (LAR). When plotted against RGR, the ULR of the $140 \mathrm{~F}_{3}$ lines was found not to be related to the RGR in a statistical sense (Fig. 1a). 
Table 2 Summary of the results of the $140 \mathrm{~F}_{3}$ lines. Mean value across all line means, the ratio of maximum and minimum values of the line means, significance of the line differences, estimate of the broad-sense heritability, as well as the ranking of both parents in the distribution of the 140 lines, expressed as percentiles. Trait abbreviations and significance levels are as in Table 1

\begin{tabular}{|c|c|c|c|c|c|c|}
\hline Abbrevation & $\begin{array}{l}\text { Mean } \\
\text { value }\end{array}$ & $\begin{array}{l}\text { Maximum/ } \\
\text { minimum }\end{array}$ & $\begin{array}{l}\text { Difference } \\
\text { between lines }\end{array}$ & $\begin{array}{l}\text { Broad-sense } \\
\text { heritability }\end{array}$ & $\begin{array}{l}\text { Ranking of } \\
\text { Ashqelon parent }\end{array}$ & $\begin{array}{l}\text { Ranking of } \\
\text { Mehola parent }\end{array}$ \\
\hline \multicolumn{7}{|l|}{ Growth } \\
\hline TDM & 1.96 & 2.0 & $* * *$ & 0.27 & 100 & 3 \\
\hline RGR & 264 & 1.2 & $* * *$ & 0.22 & 2 & 74 \\
\hline ULR & 14.0 & 1.2 & NS & 0.09 & 34 & 53 \\
\hline LAR & 19.0 & 1.3 & $* * *$ & 0.18 & 23 & 65 \\
\hline SLA & 38.6 & 1.3 & $* * *$ & 0.14 & 55 & 70 \\
\hline SLAy & 35.5 & 1.3 & $* * *$ & 0.17 & 8 & 71 \\
\hline LMF & 0.49 & 1.2 & $* * *$ & 0.32 & 5 & 45 \\
\hline SMF & 0.21 & 1.3 & $* * *$ & 0.23 & 78 & 40 \\
\hline $\mathrm{RMF}$ & 0.30 & 1.3 & $* * *$ & 0.26 & 84 & 62 \\
\hline \multicolumn{7}{|l|}{ Physiology } \\
\hline $\mathrm{PS}_{\mathrm{A}}$ & 16.8 & 1.3 & $* * *$ & 0.23 & 27 & 47 \\
\hline $\mathrm{PS}_{\mathrm{M}}$ & 593 & 1.3 & + & 0.09 & 8 & 63 \\
\hline Gs & 360 & 2.4 & $*$ & 0.09 & 14 & 33 \\
\hline WUE & 7.2 & 1.7 & NS & 0.00 & 85 & 63 \\
\hline $\mathrm{LR}_{\mathrm{M}}$ & 45.5 & 1.6 & NS & 0.01 & 47 & 56 \\
\hline $\mathrm{RR}_{\mathrm{M}}$ & 60.9 & 1.9 & NS & 0.00 & 32 & 77 \\
\hline FCI & 0.81 & 1.1 & & & 6 & 29 \\
\hline $\mathrm{LCC}_{\mathrm{M}}$ & 398 & 1.1 & & & 15 & 64 \\
\hline $\mathrm{LNC}_{\mathrm{A}}$ & 105 & 1.4 & & & 92 & 57 \\
\hline $\mathrm{LNC}_{\mathrm{M}}$ & 71 & 1.2 & & & 12 & 65 \\
\hline $\mathrm{NO}_{3}$ & 83 & 2.0 & & & 70 & 58 \\
\hline PNUE & 159 & 1.3 & & & 4 & 41 \\
\hline \multicolumn{7}{|l|}{ Morphology } \\
\hline SeedM & 24.1 & 2.6 & $* * *$ & 0.42 & 100 & 4 \\
\hline LMD & 86.4 & 1.6 & + & 0.12 & 78 & 43 \\
\hline LThick & 328 & 1.4 & + & 0.11 & 65 & 51 \\
\hline LWidth & 10.2 & 1.5 & $* * *$ & 0.45 & 100 & 1 \\
\hline LLength & 244 & 1.5 & $* * *$ & 0.36 & 96 & 14 \\
\hline LAngle & 14 & $>10$ & $* * *$ & 0.18 & 65 & 85 \\
\hline SMD & 104 & 1.2 & $* * *$ & 0.19 & 91 & 48 \\
\hline RMD & 82 & 1.2 & $* * *$ & 0.39 & 97 & 58 \\
\hline RLength & 55 & 2.1 & $* * *$ & 0.14 & 52 & 32 \\
\hline Height & 12.8 & 4.1 & $* * *$ & 0.31 & 89 & 11 \\
\hline No. till & 6.7 & 2.0 & $* * *$ & 0.22 & 31 & 75 \\
\hline No. leaf & 18.2 & 1.9 & $* * *$ & 0.27 & 53 & 70 \\
\hline
\end{tabular}

Calculation of the slope of the relationships after $\ln$ transformation give the so-called growth response coefficients (GRCs), which indicate to what extent a proportional change in each of the growth parameters is accompanied by a proportional change in RGR (Poorter and Van der Werf 1998). They generally range from 0 (no relationship) to 1 (1:1 relationship) and add up to 1.0 in the case of ULR and LAR, or in the case of ULR, SLA and LMF. For the $140 \mathrm{~F}_{3}$ lines, the GRC value for ULR was low (0.08). The relationship between RGR and LAR, on the other hand, was highly significant, with a GRC value of 0.93 (Fig. 1b). Both SLA and LMF contributed to the higher LAR of the fast-growing genotypes, with SLA having the stronger impact (Fig. $1 \mathrm{c}, \mathrm{d})$. Similar results were found in a meta-analysis of 66 growth experiments (Poorter and Van der Werf 1998). Shipley (2002) recently found highest GRC values for ULR, and suggested that the high light intensity used in his experiment caused ULR to be more important. However, the current experiment was also conducted at high levels of light $\left(\approx 23 \mathrm{~mol} \mathrm{~m}^{-2} \mathrm{day}^{-1}\right)$. A better insight into this problem could only be obtained from comparative experiments carried out simultaneously at various light levels. Although not many of such factorial experiments have been carried out to date, the indication is that light intensity generally does not affect the GRC values (Poorter and Van der Werf 1998). However, it may affect the relative importance of ULR and LAR in cases where sun and shade species are compared (Poorter 1999).

More insight into the causation of variation in growth rate can be obtained if we understand the connections and the regulation of the complex of traits that relate physiology, chemical composition and morphology. For 25 relevant traits measured for the $140 \mathrm{~F}_{3}$ lines, we summarised the interdependencies in the upper right part of Table 3. For comparison, we summarised data from a former experiment with a range of inherently fast- and slow-growing herbaceous species from western Europe, that were grown under similar conditions, in the lower left part of Table 3 ( 24 species; data from Poorter and Remkes 1990; Poorter et al. 1990; Poorter and Bergkotte 1992; Poorter and Farquhar 1994). For Hordeum there is a group of variables that often shows 
Fig. 1 Line means of a ULR, b LAR, c SLA and d LMF for $140 \mathrm{~F}_{3}$ lines plotted against mean RGR. The dotted line in the graphs indicates a nonsignificant regression line, the continuous lines are significant. The open star symbols show the mean value of the two parental lines (Ashqelon to the left, Mehola to the right). GRCs for each relationship are given in the top left part of the panel, as well as the fraction of variance explained and the significance of the slope of the regression line

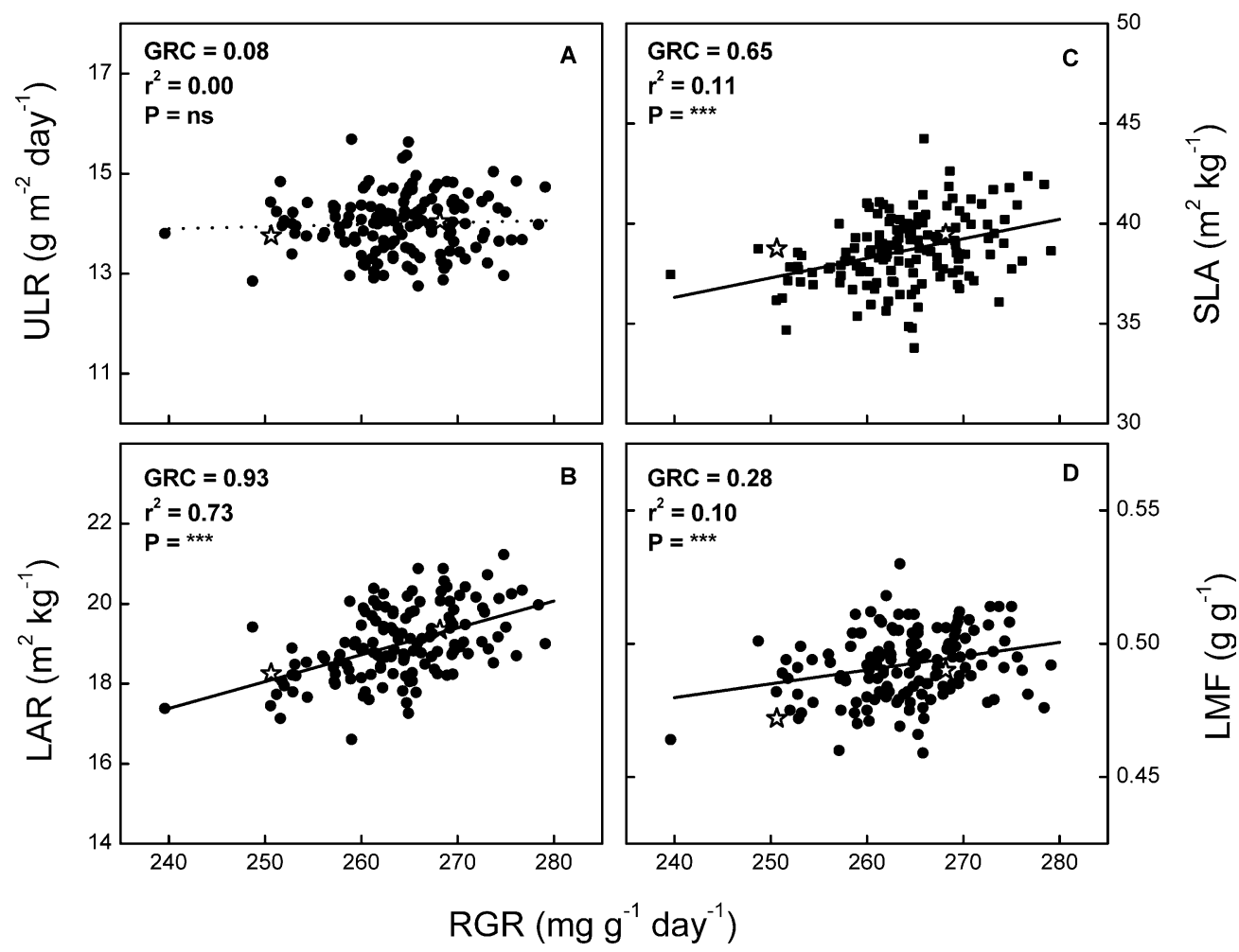

positive correlations with RGR and/or among each other. Apart from LAR and SLA, these parameters are the mass-based rates of photosynthesis and respiration, PNUE, WUE, and leaf nitrate concentration. With the exception of WUE and nitrate concentration, a similar grouping was found across species (see also Garnier 1992; Garnier and Vancaeyzeele 1994; Poorter and Evans 1998; Wright et al. 2004). A second cluster of positively related traits in $H$. spontaneum is formed by ULR, the area-based rate of photosynthesis, stomatal conductance, the organic $\mathrm{N}$ content per unit area, leaf mass density and $\mathrm{C}$ concentration. Basically, this implies that denser leaves are geared for a higher $\mathrm{C}$ gain per unit area. Such differences were found for the 24 herbaceous species as well, although less pronounced. The first group (high SLA) and the second [high photosynthesis per unit leaf area $\left(\mathrm{PS}_{\mathrm{A}}\right)$ ] show strong negative correlations with each other, especially in Hordeum.

In the third group of variables, interrelations are mixed. The fraction of daily fixed $\mathrm{C}$ that is invested in growth is positively correlated with $\mathrm{PS}_{\mathrm{A}}$, and negatively with root respiration, but overall there is no relationship with RGR. This seems at variance with the 24 species, but also in this case FCI and plant carbon concentration were minor players in a quantitative sense (Poorter et al. 1990; see also Garnier and Vancaeyzeele 1994). Thus, notwithstanding a number of details that may be different in $H$. spontaneum, the trait complex that emerges from the $140 \mathrm{~F}_{3}$ lines is quite similar to the one that is observed across species. Comparable results were found by e.g. Garnier (1992) combined with Garnier and Vancaeyzeele (1994) for 12 grass species, and Reich et al.
(1998) for nine tree species, as far as the same traits were measured.

\section{QTLs for growth traits}

As all $140 \mathrm{~F}_{3}$ lines were measured for phenotypic data, and all $F_{2}$ plants were characterised genotypically, phenotypic traits can be linked to genomic information. This is generally referred to as a QTL analysis. For each marker, a so-called LOD score is calculated, which indicates the strength of evidence for the presence of a QTL at a certain location of the genome. Fig. 2 shows the LOD profile for RGR. In total, there were three significant LOD peaks, on chromosomes 1, 2 and 5, with the RGRincreasing allele at two of these derived from the fastergrowing parent. There was also one sub-significant QTL on chromosome 6. Together, these four QTLs explained $34 \%$ of the line means variance in this trait. None of the RGR QTLs co-located with the QTL for total dry mass at the end of the experiment, which is due to the negative relationship between RGR and seed mass discussed later. Remarkably, the QTLs for RGR did not coincide with QTLs for either ULR or LAR. This is peculiar, as RGR is by definition the mathematical product of these two. Estimates of these parameters are based on averages of five individuals per line, and in such cases the product of the averages does not necessarily yield the same value as the average of the product. However, re-running the analysis with a line value for RGR which was set to be the product of the average ULR and LAR resulted in similar LOD profiles to those shown in Fig. 2. We further anal- 
Table 3 Upper right Correlation table of growth traits in $H$. spontaneum. Mean values for the $140 \mathrm{~F}_{3}$ lines were used in the calculations. Lower left Correlation table of growth traits for a range of fast- and slow-growing herbaceous species. Mean values for 24 species were used (both monocots and dicots; data from Poorter and Remkes 1990; Poorter et al. 1990; Poorter and Bergkotte (1992) and Poorter and Farquhar 1994). No leaf angle data were available for the second data set. Because leaf forms are so different for monocots and dicots, a multiple regression for leaf length, rather than a correlation, was used in the analysis of the 24 species, with the other variable of interest, as well as a dummy factor for lineage (monocot/dicot) as independent variables. Trait abbreviations are as in Table 1 . Only significant positive $(+$, open plus sign, closed plus sign) or negative (-, open minus sign, closed minus sign) correlations are shown

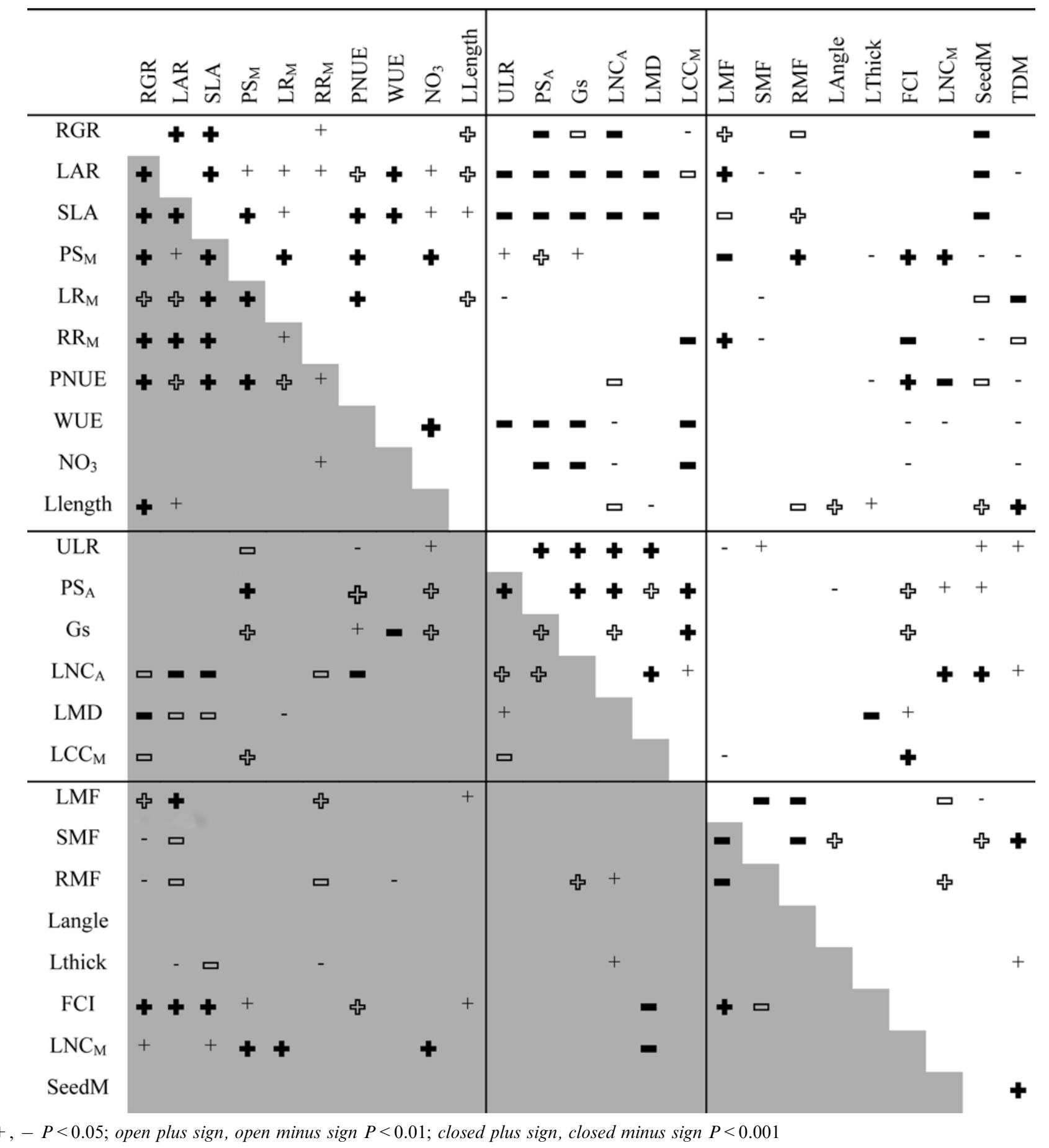

ysed this observation by plotting the additive effect for RGR against those for ULR and LAR for each marker of all linkage groups (Fig. 3). It is clear that RGR and LAR are positively correlated, as we would expect from the positive correlation at the phenotypic level (Fig. 1). Apparently, QTL-analysis does not provide us with the power to detect all of these co-locations in a significant way (cf. Beavis 1994). 


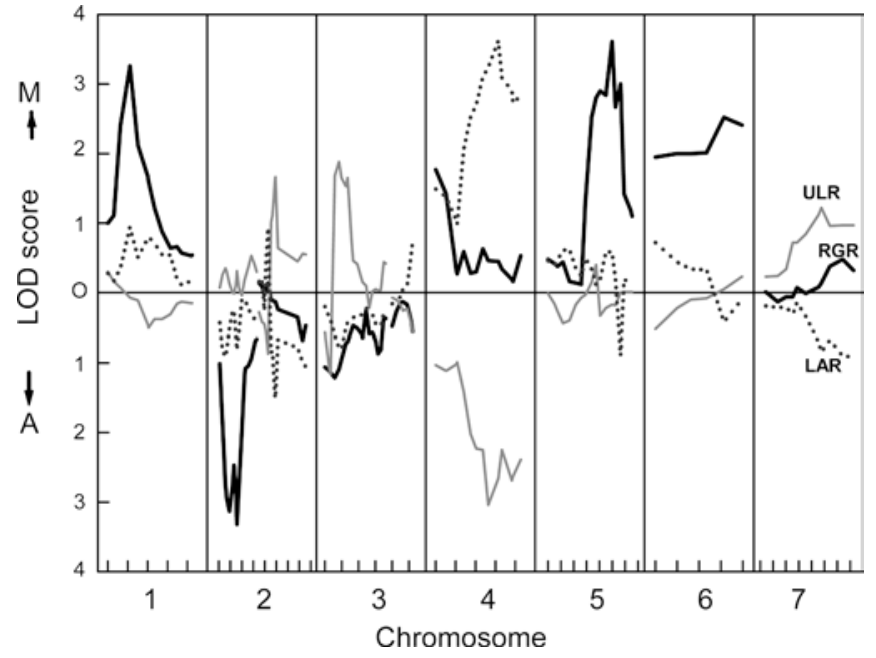

Fig. 2 LOD profiles for RGR (black continuous line), ULR (grey continuous line) and LAR (dotted line) for the seven chromosomes. To include information about the contribution of the Ashqelon and Mehola parent to the QTL, we plotted data with a positive additive contribution of Mehola at the upper part, and a positive contribution of the Ashqelon allele at the lower part

A significant QTL for LAR was found at chromosome 4, with a positive contribution by the Mehola parent, and co-located by a sub-significant QTL for ULR of opposing effect. This is in accordance with the strong negative correlations that are generally found between ULR and LAR in comparisons of different species (Konings 1989) and will be discussed in the next section. The positive contribution of the Mehola parent to LAR at chromosome 4 was visible as a QTL for one of the components of LAR (the LMF) at the same location. We found no QTLs for SLA: the highest peak LOD-scores were found in the middle of chromosomes $3 \mathrm{~A}$ and 4 , and at the end of chromosome 7 . The three LOD peaks we found in the profile are on exactly the same three chromosomes where Yin et al. (1999) found QTLs for SLA in $H$. vulgare. We did find a sub-significant QTL for the SLA of the most recently fully expanded leaf (SLAy) at chromosome 7.

\section{QTLs for physiological traits}

QTLs for physiological traits are also shown in Fig. 4. A number of co-locating QTLs related to photosynthesis were found on chromosome 4: both at growth light intensity as well as saturating light, the rate of $\mathrm{CO}_{2}$ fixation as well as stomatal conductance were found here. All these QTLs coincide with the observed QTL for ULR. No QTLs were found for the other components related to ULR (FCI, and carbon concentration of the plant, as represented by $\mathrm{LCC}_{\mathrm{M}}$ ), giving additional support to the idea that variation in ULR is mainly determined by the rate of $\mathrm{CO}_{2}$ fixation. In $H$. vulgare, Becker and Heun (1995) mapped the Rubisco activase gene (Rca) on chromosome 4. Rubisco activase activates one of the core enzymes in photosynthesis (Farquhar et al.

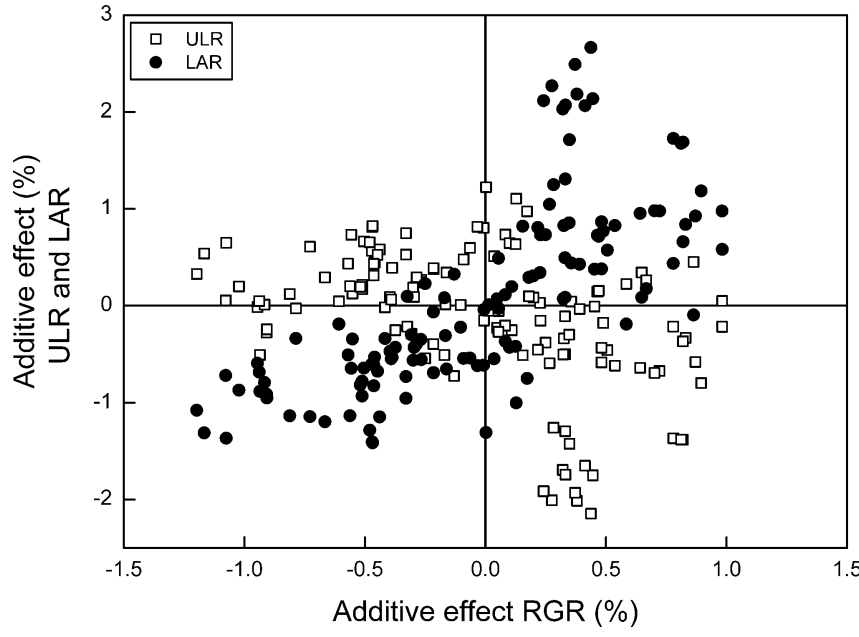

Fig. 3 Additive effect of ULR and LAR, as determined by MapQTL, plotted against the additive effect of RGR, for all molecular markers on the seven chromosomes. The additive effect was calculated for each marker as half of the difference in the trait value between the plants that had two Mehola alleles and plants that had two Ashquelon alleles at the marker. For ease of comparison, the additive effect is scaled relative to the mean value of that trait over all plants

1982). This et al. (2000) reported on a QTL for total chlorophyll content per unit leaf area on chromosome 4 in $H$. vulgare. With so many parameters of the photosynthetic process located here it may well be that there is one master switch or regulating gene that coordinates a larger part of the process of photosynthesis. Alternatively, the whole group of photosynthetic traits may be determined by the processes that act primarily on LAR. Two explanations are possible. Given the strong negative correlation between ULR and LAR, a high LAR through a higher SLA dilutes all photosynthetic compounds on an area basis, thereby possibly causing all of these compounds and rates to be decreased per unit area. A second explanation is that a high LAR would be obtained via a high LMF. High allocation to the leaves in the case of $H$. spontaneum implies lower allocation to roots (Table 3), with the consequence that fewer roots have to sustain a given amount of leaf area. This might lead to a lower leaf conductance for water and $\mathrm{CO}_{2}$, and therefore a lower rate of photosynthesis. The QTL for LAR co-locates with one for LMF of similar sign, and there is a strong positive correlation between RMF and $\mathrm{PS}_{\mathrm{M}}$, suggesting that the second explanation would be more likely (Table 4).

A second cluster of QTLs related to the photosynthetic process was found at chromosome 5. Interestingly, both QTLs for the area-based and mass-based rate of photosynthesis are found here, in compliance with the conclusion of Evans (1998) that these two can covary positively. However, the mass-based QTLs were stronger. Expressed on a leaf mass basis, C gain is generally well correlated with RGR (Poorter et al. 1990; Kitajima 1994; Reich et al. 1998), and therefore it is not that surprising to find a QTL for RGR of similar sign here as well. 


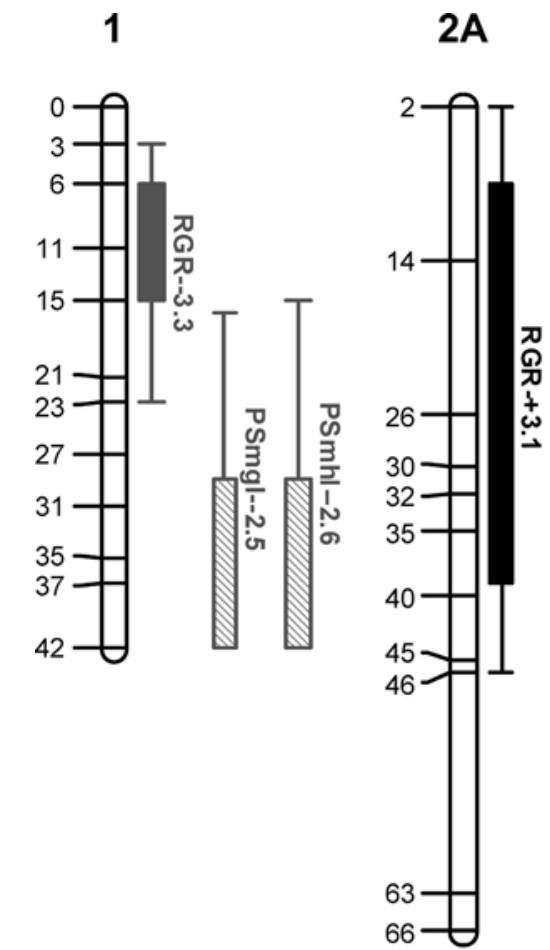

2B

$3 A$

3B

4

4
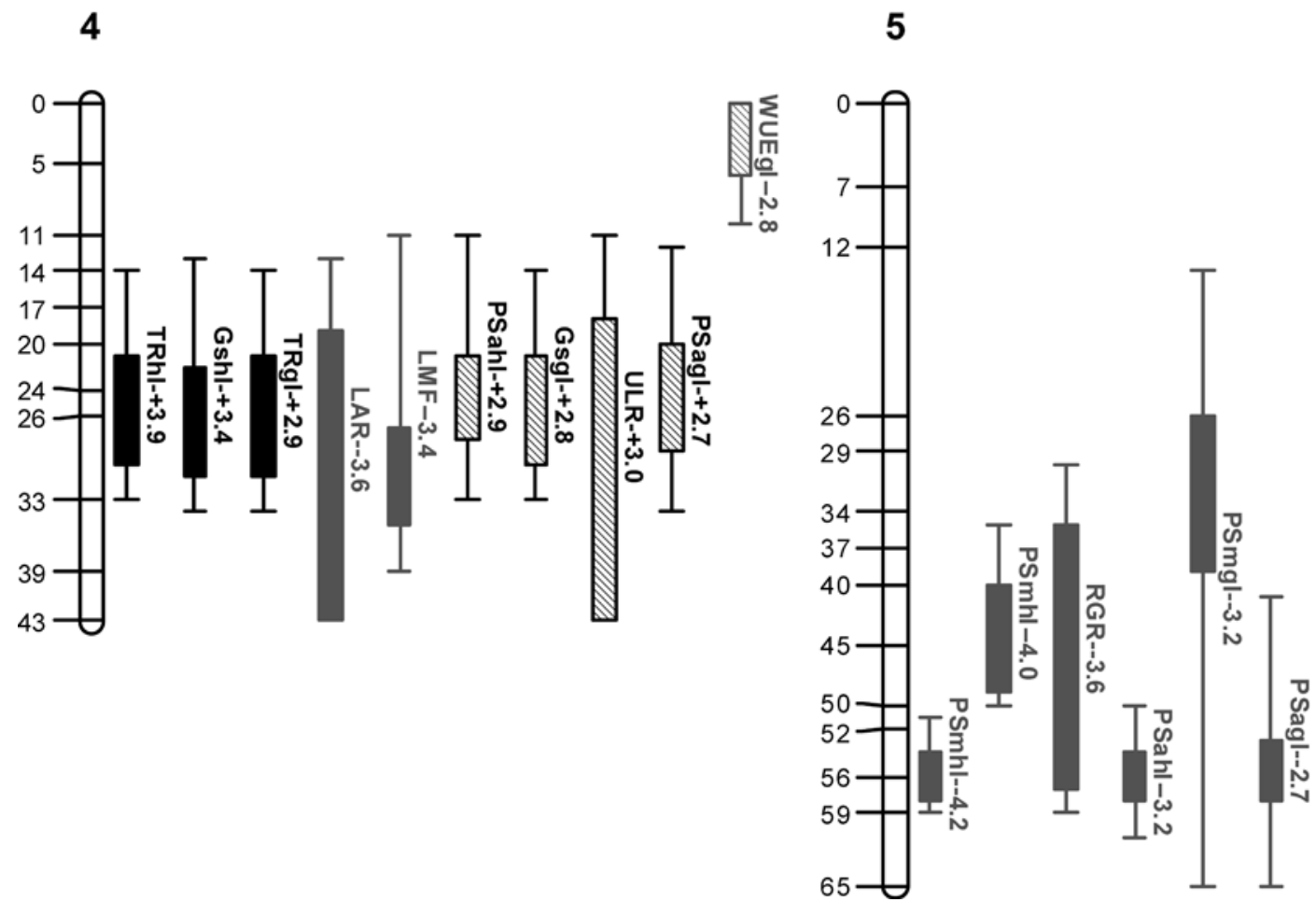

Fig. 4 Location of QTLs related to growth and physiology. QTLs with a positive effect of the Mehola allele are printed in black, those with a positive effect of the Ashqelon allele in grey. QTLs with a significant LOD score (LOD>3.1) are filled, those with a sub-

significant score $(2.5<\mathrm{LOD}<3.1)$ are hatched. Map positions are given in centiMorgan, the pertaining markers can be found in the Appendix. Linkage groups U1 and U2 are not shown, as no QTLs were mapped there 
Table 4 Quantitative trait loci for growth and physiological traits in an $H$. spontaneum $\mathrm{F}_{3}$ population. Location of peak position and LOD score at that point are given, plus the estimated total variance explained by the QTL. The additive effect is the effect of substituting a Mehola allele for a Ashqelon allele. Negative effects indi- cate that the Ashqelon parent has the positive allele. Trait abbreviations are as in Table 1. Gas exchange parameters were measured either at growth light intensity $\left(450 \mu \mathrm{mol} \mathrm{m}{ }^{-2} \mathrm{~s}^{-1}\right.$; gl $)$, or at a high light intensity $\left(1,500 \mu \mathrm{mol} \mathrm{m} \mathrm{m}^{-2} \mathrm{~s}^{-1}\right.$; hl), which was saturating photosynthesis

\begin{tabular}{|c|c|c|c|c|c|}
\hline QTLs & Chromosome & Peak position $(\mathrm{cM})$ & Peak LOD score & Percentage of variance explained & Additive effect $(\%)$ \\
\hline \multicolumn{6}{|l|}{ Growth } \\
\hline TDM & $2 \mathrm{~B}$ & 23 & 2.6 & 8 & -3.5 \\
\hline \multirow[t]{4}{*}{ RGR } & 5 & 50 & 3.6 & 9 & 0.5 \\
\hline & 1 & 11 & 3.3 & 9 & 1.0 \\
\hline & $2 \mathrm{~A}$ & 32 & 3.3 & 9 & -1.0 \\
\hline & 6 & 16 & 2.5 & 7 & 0.6 \\
\hline ULR & 4 & 26 & 3.0 & 9 & -2.0 \\
\hline LAR & 4 & 31 & 3.6 & 14 & 2.7 \\
\hline SLAy & 7 & 27 & 2.5 & 12 & 0.7 \\
\hline \multirow[t]{4}{*}{$\mathrm{LMF}$} & 7 & 2 & 4.6 & 14 & -1.2 \\
\hline & 6 & 0 & 3.8 & 3 & 1.4 \\
\hline & 7 & 27 & 3.6 & 9 & -1.2 \\
\hline & 4 & 31 & 3.4 & 14 & 1.3 \\
\hline RMF & 6 & 20 & 5.1 & 14 & -2.2 \\
\hline \multicolumn{6}{|l|}{ Physiology } \\
\hline \multirow[t]{2}{*}{$\mathrm{PS}_{\mathrm{A}}(\mathrm{gl})$} & 4 & 24 & 2.7 & 8 & -1.7 \\
\hline & 5 & 56 & 2.7 & 8 & 1.7 \\
\hline \multirow[t]{2}{*}{$\mathrm{PS}_{\mathrm{A}}(\mathrm{hl})$} & 5 & 56 & 3.2 & 10 & 2.6 \\
\hline & 4 & 24 & 2.9 & 8 & -2.2 \\
\hline $\mathrm{PS}_{\mathrm{M}}(\mathrm{gl})$ & 5 & 37 & 3.2 & 13 & 2.8 \\
\hline \multirow{3}{*}{$\mathrm{PS}_{\mathrm{M}}(\mathrm{hl})$} & 5 & 56 & 4.2 & 14 & 2.9 \\
\hline & 5 & 37 & 4.0 & 16 & 3.6 \\
\hline & 1 & 31 & 2.5 & 8 & 2.3 \\
\hline Gs (gl) & 4 & 26 & 2.8 & 9 & -7.2 \\
\hline Gs (hl) & 4 & 26 & 3.4 & 11 & -7.6 \\
\hline WUE & 4 & 0 & 2.8 & 12 & 5.6 \\
\hline $\mathrm{RRm}$ & $2 \mathrm{~B}$ & 46 & 2.6 & 10 & -4.0 \\
\hline $\mathrm{LNC}_{\mathrm{A}}$ & $2 \mathrm{~B}$ & 21 & 2.8 & 11 & -2.9 \\
\hline \multirow{2}{*}{ PNUE (gl) } & $3 \mathrm{~A}$ & 38 & 3.5 & 12 & 0.0 \\
\hline & $2 \mathrm{~B}$ & 29 & 3.1 & 10 & 2.7 \\
\hline
\end{tabular}

We detected very few QTLs for aspects of the $\mathrm{N}$ economy. The organic $\mathrm{N}$ content per unit leaf area showed a sub-significant QTL on chromosome 2B, with a QTL for PNUE in the same region, but with opposite effect (Fig. 4). The organic leaf nitrogen concentration peaked negatively on chromosome 7, co-locating with a positive QTL for LMF. None of the observed QTLs explained a large proportion of the observed variance, values predominantly ranging from 7 to $14 \%$.

\section{QTLs for morphological traits}

Consistent with the higher heritabilities (Table 1), QTLs for morphological traits were in general more significant than those for growth and physiology. The highest LOD score was for plant height, at chromosome 2A $(\mathrm{LOD}=6.3$; Fig. 5). In this region, overlapping QTLs are found for a range of traits: leaf angle, leaf width, leaf length, maximum root length and seed mass, all with a positive contribution by the Ashqelon parent. Causse et al. (1995) observed a similar co-location of these traits in maize. Leaf length was the morphological variable with the most QTLs: three significant and one sub-significant. Leaf length and width also co-located at chro- mosome 4 , both with a positive contribution of the Ashqelon parent. No QTLs were found for the components of SLA, which are leaf thickness and leaf mass density. There were QTLs with opposing effects found for both stem and root mass density.

Although seed mass varied strongly between the parents, we found only two QTLs for this trait (Fig. 5), explaining $20 \%$ of the total variation. Interestingly, they both coincided with QTLs for RGR (Fig. 4), one of opposite and one of similar sign. A negative correlation between the two parameters is often observed in interspecific comparisons (Jurado and Westoby 1992; Marañón and Grubb 1993), but not necessarily in intraspecific comparisons (Clevering 1999; Meerts and Garnier 1996). Part of the explanation could be that plants from large seeds are larger, and larger plants generally have a lower RGR. No correlation between RGR and seed mass was found in comparisons of four (Chapin et al. 1989) or 15 (Van Rijn 2001) Hordeum species, nor in a comparison of $28 \mathrm{H}$. spontaneum populations (Van Rijn et al. 2000). In all of these experiments with Hordeum species, as well as in the current contrast between two parents, relative differences in vegetative shoot biomass at the end of the experimental growth period was determined more by relative differ- 
1

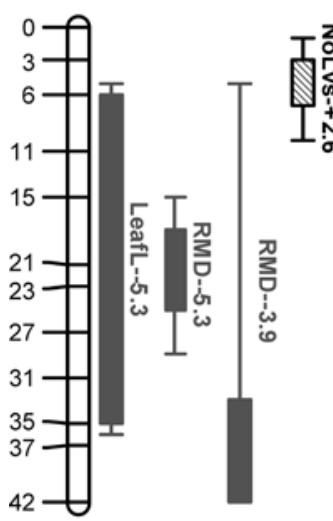

2A

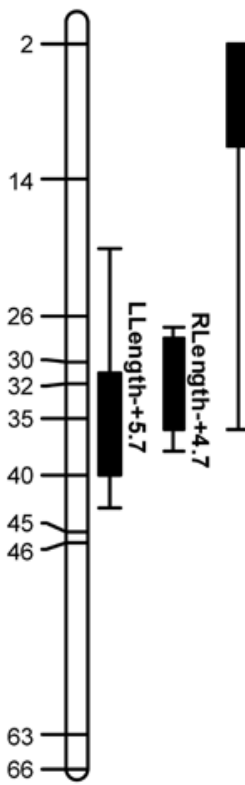

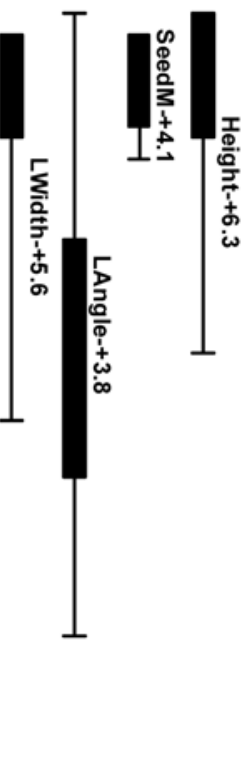

2B

3A

3B

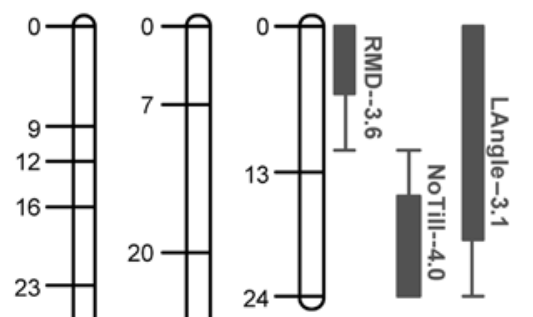

4

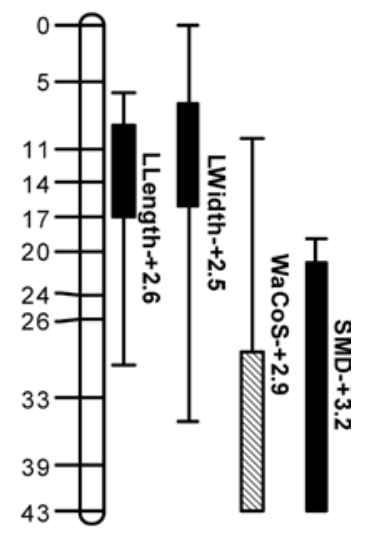

5

6

7
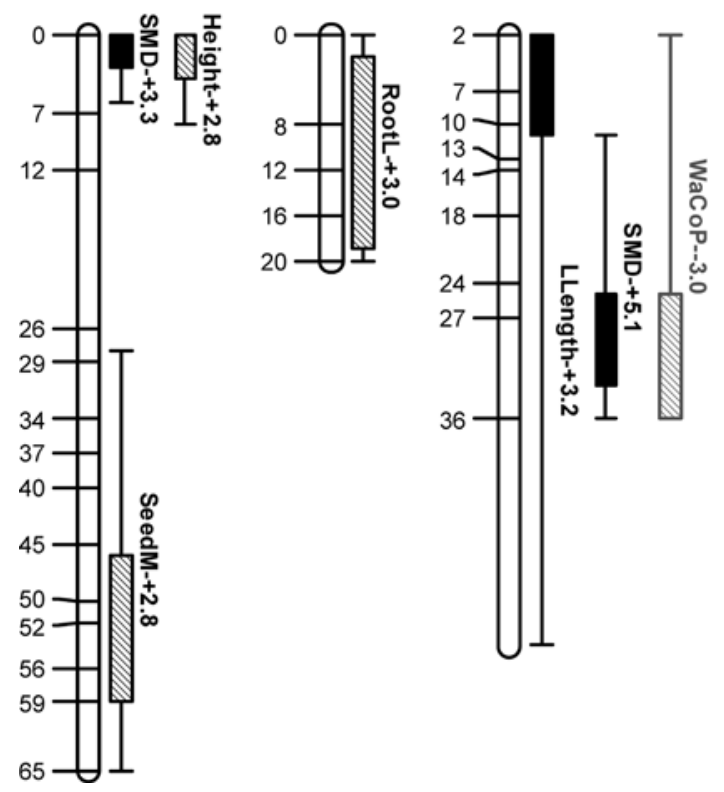

Fig. 5 Location of QTLs for morphological parameters. For more information see the legend of Fig. 4

ences in seed mass at the start than by differences in RGR (Table 5).

Master switches

We now turn to the question to what extent the trait complex of slow- versus fast-growth, present in the $\mathrm{F}_{3}$ lines investigated here, could be regulated by one or a few master switches (Chapin et al. 1993). An indication for a master switch is found at chromosome 4, where many factors related to photosynthesis co-locate. Is this clear evidence of a complex of traits pleiotropically regulated by a master gene? First, one has to be aware that confidence limits of each QTL are wide, and co-location does not necessarily imply that factors are regulated by the same gene (Beavis 1994). Second, correlations of physiological traits may merely indicate a causal chain of 
Table 5 Quantitative trait loci for morphological parameters in an $\mathrm{F}_{3}$ population of $H$. spontaneum. For more information see the header for Table 4

\begin{tabular}{|c|c|c|c|c|c|}
\hline Suggestive QTLs & chromosome & Peak position (cM) & Peak LOD score & Percentage of variance explained & Additive effect $(\%)$ \\
\hline \multirow[t]{2}{*}{ SeedM } & $2 \mathrm{~A}$ & 2 & 4.1 & 12 & -9.9 \\
\hline & 5 & 50 & 2.8 & 8 & -4.2 \\
\hline \multirow[t]{2}{*}{ LWidth } & $2 \mathrm{~A}$ & 7 & 5.6 & 23 & -6.2 \\
\hline & 4 & 11 & 2.5 & 7 & -2.5 \\
\hline \multirow[t]{4}{*}{ LLength } & $2 \mathrm{~A}$ & 35 & 5.7 & 14 & -4.1 \\
\hline & 1 & 15 & 5.3 & 14 & 4.3 \\
\hline & 7 & 2 & 3.2 & 7 & -3.0 \\
\hline & 4 & 14 & 2.6 & 9 & -1.1 \\
\hline \multirow[t]{2}{*}{ LAngle } & $2 \mathrm{~A}$ & 32 & 3.9 & 11 & -25.1 \\
\hline & $3 \mathrm{~B}$ & 5 & 3.1 & 10 & 17.6 \\
\hline \multirow[t]{3}{*}{ SMD } & 7 & 27 & 5.1 & 18 & -2.7 \\
\hline & 5 & 0 & 3.3 & 11 & 0.5 \\
\hline & 4 & 43 & 3.2 & 9 & 1.8 \\
\hline \multirow[t]{3}{*}{ RMD } & 1 & 21 & 5.3 & 14 & -2.4 \\
\hline & 1 & 37 & 3.9 & 12 & -2.3 \\
\hline & $3 \mathrm{~B}$ & 0 & 3.6 & 10 & 1.5 \\
\hline \multirow[t]{2}{*}{ RLength } & $2 \mathrm{~A}$ & 30 & 4.7 & 14 & -6.1 \\
\hline & 6 & 16 & 3.0 & 9 & -5.2 \\
\hline \multirow[t]{2}{*}{ Height } & $2 \mathrm{~A}$ & 7 & 6.3 & 24 & -20.4 \\
\hline & 5 & 0 & 2.8 & 8 & -10.5 \\
\hline
\end{tabular}

events, rather than independent pleiotropic effects. For example, if plants regulate stomatal conductance such that the intercellular $\mathrm{CO}_{2}$ pressure is constant (Wong et al. 1979), then photosynthesis and stomatal conductance will co-locate, without the necessity of a master switch regulating these traits independently at the same time. Notwithstanding these arguments, it cannot be excluded that a master switch is present in this case, with the rate of photosynthesis and stomatal conductance mapping in this region, as well as Rubisco activase and chlorophyll content.

The situation is different if we consider the traits related to RGR. From previous experiments we had expected that a gene controlling the level of, or sensitivity for, gibberellic acids (GAs) would be a likely candidate for such a master gene. A positive correlation between RGR and endogenous GA concentration has been found for Zea mays by Rood et al. (1990) and for Lycopersicon esculentum by Nagel et al. (2001), and the application of GA increased SLA and RGR in Plantago major (Dijkstra et al. 1990). In our analysis, four different QTLs were found for RGR. There is co-location of this parameter with other traits, most notably seed mass at chromosome $2 \mathrm{~A}$, mass-based photosynthesis at chromosome 5, and LMF at chromosome 6. However, a number of other traits in the fast- versus slow-growth complex are located at various other regions of the genome: a fast mass-based rate of root respiration is found at chromosome 2B; and PNUE - also a characteristic of fast-growing species (Poorter and Evans 1998) - is located at chromosome 3A. A QTL for SLA, which is often a component of the fast-growth complex, is not found at all, but there is an LOD peak for SLA at the same place as for PNUE, which is to be expected from physiological correlations, and a QTL for SLA of the youngest leaf on chromosome 7. Leaf nitrogen concentration is another parameter that is generally positively associated with RGR, but is not co-locating. Thus, we see that various parts of the trait complex show up as QTLs in distinct regions of the genome. Moreover, as mentioned above, we covered only half of the full genome with our map, which may imply that we miss out on various QTLs. Keeping this in mind, the data presented here does not support the hypothesis of one or two master genes regulating a whole complex of growthrelated traits.

\section{Conclusions}

In an $\mathrm{F}_{3}$ population derived from a cross of two $H$. spontaneum parents from contrasting origin, we found that a trait complex existed that showed large similarity with that across a wide range of inherently fast- and slow-growing herbaceous species. No QTLs with strong pleiotropic effects were observed for a range of traits in the complex. Rather, various traits showed up at different parts of the genome. Thus, at least for $H$. spontaneum, we did not find experimental evidence for one or two master switches regulating the fast- and slow-growth complex.

Acknowledgements We thank Arjen Biere, Basten Snoek, Brian Forster, Jos van Damme, Margreet ter Steege, Rens Voesenek and Ton Peeters for valuable suggestions and comments during research and the writing of the manuscript. The Earth and Life Science Foundation (ALW), which is subsidised by the Netherlands Organisation for Scientific Research (NWO), supported this study financially. 


\section{Appendix: the $\boldsymbol{H}$. spontaneum map}

AFLP and SSR markers

Seventeen primer combinations were selected: E33M54, E33M61, E35M48, E35M54, E35M61, E38M55, E38M58, E42M51 and E45M55 (Qi and Lindhout 1997), E37M32, E37M33, E40M38, E41M32, E41M40, E42M32, E42M40 (Becker et al. 1995) and E31M55. DNA was isolated from 2-week-old leaves of the $233 \mathrm{~F}_{2}$ plants, using the CTAB method (Ausubel et al. 1999). The AFLP protocol was essentially as described in Vos et al. (1995). The DNA was double digested with the restriction enzymes $E c o$ RI and $M s e I$. The EcoRI-specific primers were labeled with either 700 or $800 \mathrm{~nm}$ infra-red dye (IRD700, IRD800) for detection with an automated laser sequencer (Li-Cor). In addition, markers generated by the primer combinations E32 M61, E33 M55, E39 M61, E42 M48 and E38 M54 (Qi and Lindhout 1997) were genotyped co-dominantly by Keygene.

Separately, a set of 13 SSR markers was used (Ramsay et al. 2000). The primers were labelled with either IRD700 or IRD800 for the Li-Cor sequencer. Approximately $20 \mathrm{ng}$ of template DNA was used in the PCR reaction mixture, which further consisted of $1 \times$

1

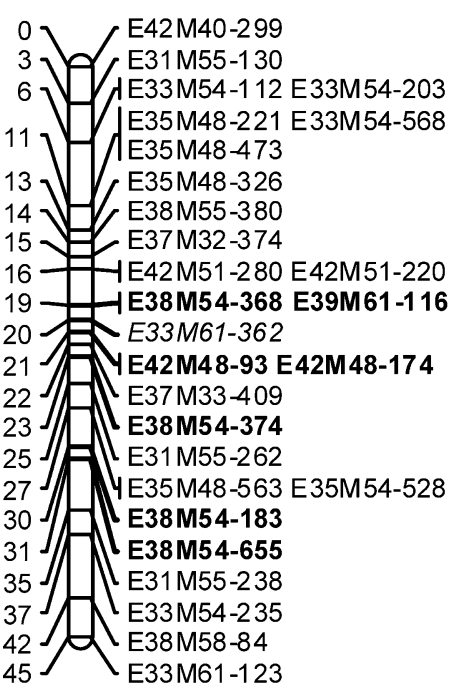

2A

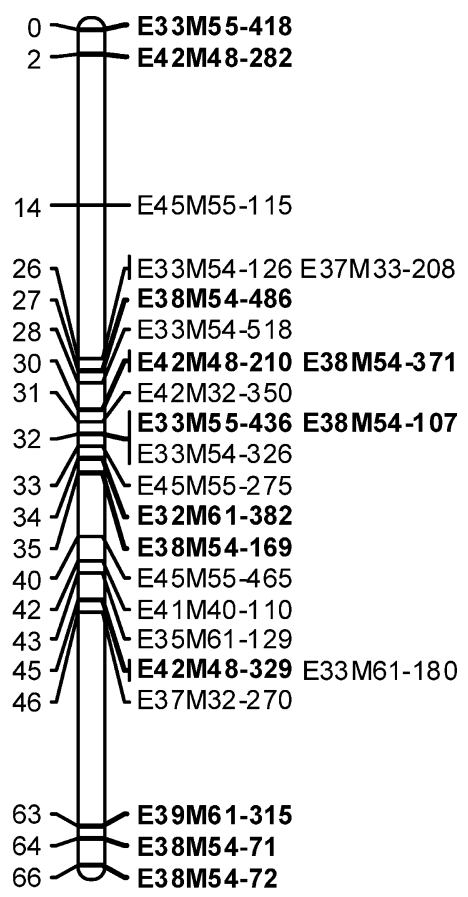

PCR buffer, 0.5 U Ampli Taq polymerase (Perkin Elmer Inc., Wellesley, Mass., USA), $200 \mu \mathrm{M}$ dNTPs and 1 pmol forward and reverse primer. The reaction volume was $10 \mu \mathrm{l}$. Four different PCR programs were used for amplification as described by Ramsay et al. (2000).

\section{Map construction}

The AFLP markers from 17 primer combinations were scored dominantly as the absence or presence of an amplification product. The scoring was done by eye with the help of the Cross Checker program (Buntjer 1999). The markers from five additional primer combinations were generated and scored co-dominantly by Keygene using their QuantarPro software, which enables a distinction between the homozygous and heterozygous state based on band intensity. The AFLP marker names were designated from the primer combination and size of the amplification product. SSRs were scored co-dominantly.

During the crossing process we kept track of the structure of the mapping population. Inspection of the data revealed that some of the $F_{2}$ sub-families did not segregate for a number of markers, due to partial homozygosity of the parental $F_{1}$ plant. This resulted

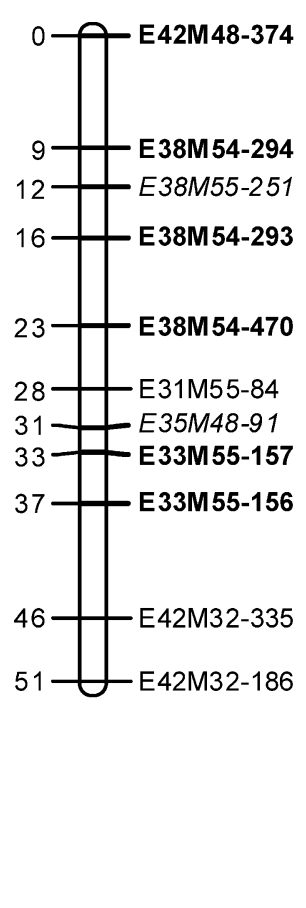

3A

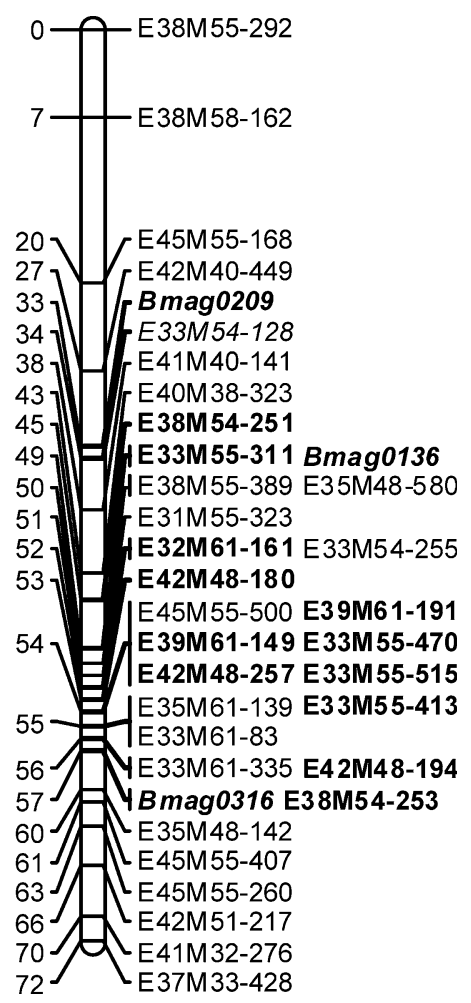

Fig. 6 The linkage map of wild barley, H. spontaneum. Assignment of linkage groups to barley chromosomes $1 \mathrm{H}$ to $7 \mathrm{H}$ as described in the text. Linkage groups U1 and U2 are unassigned. AFLP marker identifiers are composed of primer combinations and estimated length of the amplification product. Co-dominant markers are indicated in bold, and markers used in identification of chromosomes are indicated in italics. Clusters of markers mapping to the same position (within $1 \mathrm{cM}$ ) are indicated by vertical bars to the left of the clusters 
3B

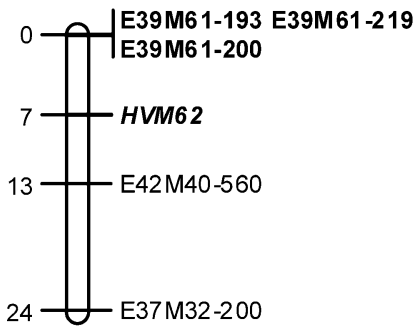

4

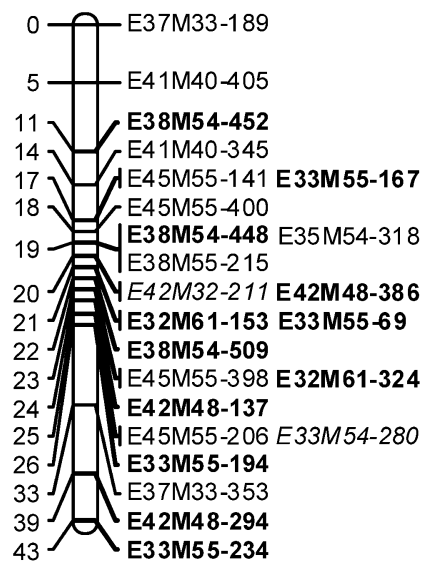

5

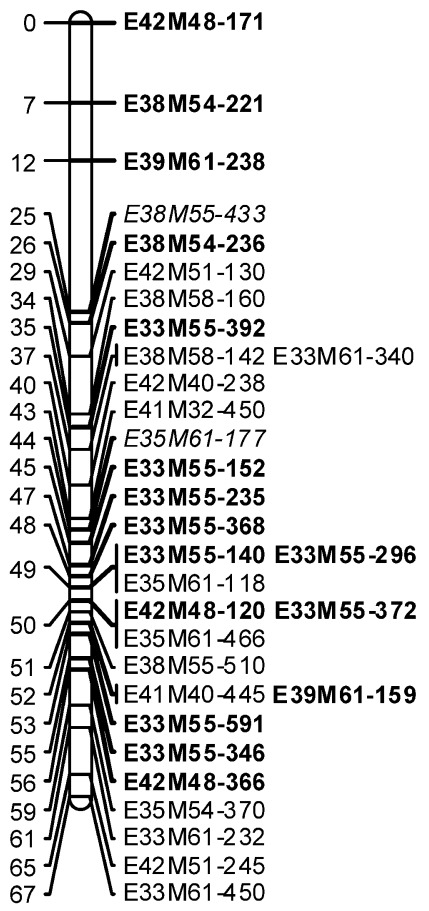

6

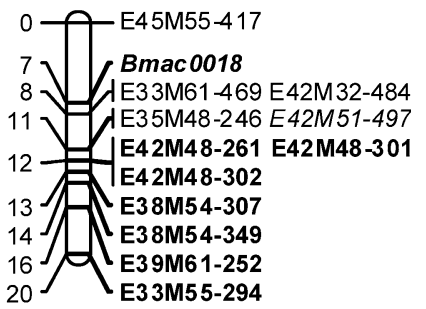

7

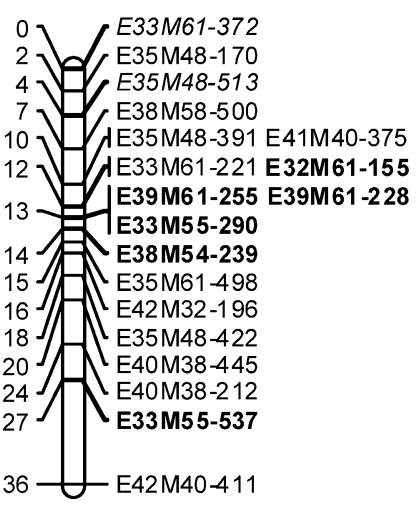

U1

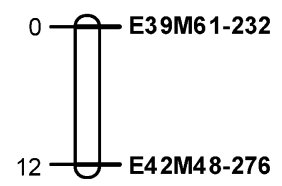

U2

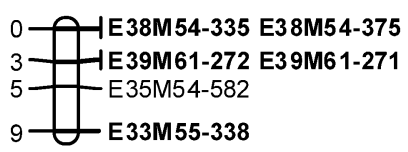

Fig. 6 (Contd.)

from heterozygosity at such a marker for one of the parents of our cross. Neglecting this would affect the mapping results, i.e. by segregation distortion of these markers and an overestimation of recombination frequency between 'affected' and 'non-affected' markers (P. Stam, unpublished results). Therefore, for each marker we checked its segregation in each $F_{2}$ sub-family and removed data from non-segregating sub-families.

With the corrected data set, a linkage map was constructed using the JoinMap 3.0 software package (Van Ooijen and Voorrips 2000). Linkage groups were assigned using an LOD threshold of 5.0. Kosambi's mapping function was used to calculate map distances.
To assign the linkage groups to known barley chromosomes, SSR loci (Ramsay et al. 2000) as well as AFLP markers in common with earlier maps from several cultivated barley populations L94 $\times$ Vada (Qi et al. 1998), L94 × 115-6 (P. Lindhout, personal communication), Apex $\times$ Prisma (Yin et al. 1999) and Proctor $\times$ Nudinka (Becker et al. 1995) were used.

\section{Linkage map}

The marker data revealed that the Ashqelon parent must have been heterozygous: $59 \%$ of the Ashqelon-specific markers did not segregate in at least one $\mathrm{F}_{2}$ sub-family. 
Table 6 The linkage groups, the chromosomes to which they are assigned, number of markers in each linkage group, length of linkage group, the relevant maps the chromosomes were based on and common markers linking the map of H. spontaneum Ashqelon $\times$ Mehola to other Hordeum maps

\begin{tabular}{|c|c|c|c|c|c|}
\hline $\begin{array}{l}\text { Linkage } \\
\text { group }\end{array}$ & $\begin{array}{l}\text { Hordeum } \\
\text { chromosome }\end{array}$ & $\begin{array}{l}\text { No. } \\
\text { markers }\end{array}$ & $\begin{array}{l}\text { Length } \\
\text { (cM) }\end{array}$ & Assignment & $\begin{array}{l}\text { No. common } \\
\text { markers }\end{array}$ \\
\hline 1 & $1(7 \mathrm{H})$ & 28 & 45 & L94 × Vada (Qi et al. 1998) & 1 \\
\hline $2 \mathrm{~B}$ & $2(2 \mathrm{H})$ & 11 & 51 & $\begin{array}{l}\text { L94 × Vada (Qi et al. } 1998) \\
\text { L94 } \times 116-5(\text { P. Lindhout, personal communication })\end{array}$ & 2 \\
\hline $3 \mathrm{~A}$ & $3(3 \mathrm{H})$ & 36 & 72 & $\begin{array}{l}\text { Lina } \times \text { HS }(\text { Ramsay et al. 2000) } \\
\text { L94 × Vada (Qi et al. 1998) }\end{array}$ & 4 \\
\hline 5 & $5(1 \mathrm{H})$ & 32 & 67 & L94 × Vada (Qi et al. 1998) & 2 \\
\hline 6 & $6(6 \mathrm{H})$ & 13 & 20 & $\begin{array}{l}\text { Tentative } \\
\text { Lina } \times \text { HS (Ramsay et al. 2000) } \\
\text { L94 × Vada (Qi et al. 1998) } \\
\text { Prisma } \times \text { Apex (Yin et al. 1999) }\end{array}$ & - \\
\hline
\end{tabular}

Heterozygosity was less prominent in the Mehola parent; with $7 \%$ of the Mehola-specific markers not segregating in at least one $\mathrm{F}_{2}$ sub-family. As a consequence, $45 \%$ of the markers contained no useful linkage information. After adjustment, 202 markers (196 AFLP and six SSR) could be mapped without problems.

The resulting linkage map is shown in Fig. 6. The markers are distributed over 11 linkage groups. Except for group U1, each linkage group contains both dominant and co-dominant markers. These co-dominant markers provided sufficient anchors to enable integration of the parental maps. The total map length equals $445 \mathrm{cM}$. This makes an average of 18 markers per linkage group, the range being from two to 36 . The average distance between two markers was $2.2 \mathrm{cM}$. No gaps between two adjacent markers were larger than 20 $\mathrm{cM}$.

The assignment of linkage groups to barley chromosomes is based on AFLPs and SSRs that are in common with other linkage maps of cultivated barley (Table 6). Seven of the 11 linkage groups could unambiguously be assigned to known barley chromosomes. Three groups (2A, U1 and U2) did not contain any common markers, and one group (6) contained markers that mapped to different chromosomes in other mapping populations. Groups 2A and 6 were tentatively assigned to chromosomes based on weak linkage of some markers that were not mapped in our population, but have been mapped in at least one of the other populations. Linkage groups U1 and U2 remained unassigned, due to lack of markers shared with other maps.

The $\chi^{2}$ values for goodness-of-fit ranged from 0.83 to 1.60 for the 11 linkage groups, indicating a good overall fit. Therefore, even though the current map had to be assembled by removing a substantial number of markers, the remaining data still resulted in a reliable map that can serve as a basis for further linkage and QTL mapping.

\section{References}

Ausubel FM, Brent R, Kingston RE, Moore DD, Seidman JG, Smith JA, Struhl K (1999) In: Short protocols in molecular biology: a compendium of methods from current protocols in molecular biology, 4th edn. Wiley, New York, pp 2.11-2.12

Beavis WD (1994) The power and deceit of QTL experiments: lessons from comparative QTL studies. In: Wilkinson DB (ed) 49th Annual Conference and Sorghum Research Conference. American Seed Trade Association, Chicago, pp 250-266

Becker J, Heun M (1995) Barley microsatellites: allele variation and mapping. Plant Mol Biol 27:835-845

Becker J, Vos P, Kuiper M, Salamini F, Heun M (1995) Combined mapping of AFLP and RFLP markers in barley. Mol Genet Genomics 249:65-73

Biere A (1996) Intra-specific variation in relative growth rate: impact on competitive ability and performance of Lychnis flos-cucili in habitats differing in soil fertility. Plant Soil 182:313327

Brown AHD, Zohary D, Nevo E (1978) Outcrossing rates and heterozygosity in natural populations of Hordeum spontaneum Koch in Israel. Heridity 41:49-62

Buntjer JB (1999) Cross checker fingerprint analysis software, v. 2.9, Wageningen University and Research Centre, The Netherlands

Cataldo DA, Haroon M, Schrader LF, Youngs VL (1975) Rapid colorimetric determination of nitrate in plant tissue by nitration of salicylic acid. Comm Soil Sci Plant Anal 6:71-80

Causse M, Rocher JP, Henry AM, Charcosset A, Prioul JL, de Vienne D (1995) Genetic dissection of the relationship between carbon metabolism and early growth in maize, with emphasis on key-enzyme loci. Mol Breed 1:259-272

Chapin FS, Groves RH, Evans LT (1989) Physiological determinants of growth rate in response to phosphorous supply in wild and cultivated Hordeum species. Oecologia 79:96-105

Chapin FS, Autumn K, Pugnaire F (1993) Evolution of suites of traits in response to environmental stress. Am Nat 142:s78-s92 
Clevering OA (1999) Between- and within-population differences in Phragmites australis 1 . The effects of nutrients on seedling growth. Oecologia 121:447-457

Dijkstra P, Reegen HT, Kuiper PJC (1990) Relation between relative growth rate, endogenous gibberellins, and the response to gibberellic acid for Plantago major. Physiol Plant 79:629-634

Elberse I (2002) Genetic analysis of growth characteristics in Hordeum spontaneum under nutrient limitation. $\mathrm{PhD}$ thesis, Utrecht University

Ellis RP, Forster BP, Robinson D, Handley LL, Gordon DC, Russel JR, Powell W (2000) Wild barley: a source of genes for crop improvement in the 21st century? J Exp Bot 51:9-17

El-Lithy ME, Clerkx EJM, Ruys GJ, Koornneef M, Vreugdenhil D (2004) Quantitative trait locus analysis of growth-related traits in a new arabidopsis recombinant inbred population. Plant Physiol 135:444-458

Evans GC (1972) The quantitative analysis of plant growth. Blackwell, Oxford

Evans JR (1998) Photosynthetic characteristics of fast- and slowgrowing species. In: Lambers $\mathrm{H}$, Poorter $\mathrm{H}$, van Vuuren $\mathrm{M}$ (eds) Inherent variation in plant growth, physiological mechanisms and ecological consequences. Backhuys, Leiden, pp 101119

Farquhar GD, O'Leary MH, Berry JA (1982) On the relationship between carbon isotope discrimination and the intercellular carbon dioxide concentration in leaves. Aust J Plant Physiol 9:121-137

Garnier E (1992) Growth analysis of congeneric annual and perennial grass species. J Ecol 80:665-675

Garnier E, Vancaeyzeele S (1994) Carbon and nitrogen content of congeneric annual and perennial species: relationships with growth. Plant Cell Environ 17:399-407

Grime JP (1979) Plant strategies and vegetation processes. Wiley, Chichester

Grime JP, Hunt R (1975) Relative growth rate: its range and adaptive significance in a local flora. J Ecol 63:393-422

Hervé D, Fabre F, Flores Berrios E, Leroux N, Al Chaarani G, Planchon C, Sarrafi A, Gentzbittel L (2001) QTL analysis of photosynthesis and water status traits in sunflower (Helianthus annuus L.) under greenhouse conditions. J Exp Bot 52:18571864

Ivandic V, Hackett CA, Zhang ZJ, Staub JE, Nevo E, Thomas WTB, Forster BP (2000) Phenotypic responses of wild barley to experimentally imposed water stress. J Exp Bot 51:2021-2029

Jaglo-Ottosen KR, Gilmour SJ, Zarka DG, Schabenberger O, Thomashow MF (1998) Arabidopsis CBF1 overexpression induces COR genes and enhances freezing tolerance. Science 280:104-106

Jansen RC, Stam P (1994) High resolution of quantitative traits into multiple loci via interval mapping. Genetics 136:1447-1455

Jurado E, Westoby M (1992) Seedling growth in relation to seed size among species of arid Australia. J Ecol 80:407-416

Kitajima K (1994) Relative importance of photosynthetic traits and allocation patterns as correlates of seedling shade tolerance of 13 tropical trees. Oecologia 98:419-428

Konings H (1989) Physiological and morphological differences between plants with a high NAR or a high LAR as related to environmental conditions. In: Lambers $\mathrm{H}$, Cambridge ML, Konings H, Pons TL (eds) Causes and consequences of variation in growth rate and productivity in plants. SPB, The Hague, pp 101-123

Lambers H, Poorter H (1992) Inherent variation in growth rate between higher plants: a search for physiological causes and ecological consequences. Adv Ecol Res 23:187-261

Lander ES, Botstein D (1989) Mapping Mendelian factors underlying quantitative traits using RFLP linkage maps. Genetics 121:185-199

Maleck K, Levine A, Eulgem T, Morgan A, Schmid J, Lawton KA, Dangl JL, Dietrich RA (2001) The transcriptome of Arabidopsis thaliana during systemic acquired resistance. Nat Genet 26:403410
Marañón T, Grubb PJ (1993) Physiological basis and ecological significance of the seed size and relative growth rate relationship in Mediterranean annuals. Funct Ecol 7:591-599

Meerts P, Garnier E. (1996) Variation in relative growth rate and its components in the annual Polygonum aviculare in relation to habitat disturbance and seed size. Oecologia 108:438-445

Mian MAR, Ashley DA, Vencill WK, Boerma HR (1998) QTLs conditioning early growth in a soybean population segregating for growth habit. Theor Appl Genet 97:1210-1216

Nagel OW, Konings H, Lambers H (2001) Growth rate and biomass partitioning of wildtype and low-gibberellin tomato (Solanum lycopersicum) plants growing at a high and low nitrogen supply. Physiol Plant 111:33-39

Nevo E (1992) Origin, evolution, population genetics and resources for breeding of wild barley, Hordeum spontaneum in the Fertile Crescent. In: Shewry PR (ed) Barley genetics, biochemistry, molecular biology and biotechnology. CAB International, Wallingford, pp 19-43

Nevo E, Zohary D, Brown AHD, Haber M (1979) Genetic diversity and environmental associations of wild barley, Hordeum spontaneum, in Israel. Evolution 33:815-833

Nevo E, Beiles A, Gutterman Y, Storch N, Kaplan D (1984) Genetic resources of wild cereals in Israel and vicinity. II. Phenotypic variation within and between populations of wild barley Hordeum spontaneum. Euphytica 33:737-756

Poorter L (1999) Growth response of 15 rainforest tree species to a light gradient: the relative importance of morphological and physiological traits. Funct Ecol 13:396-410

Poorter H (2002) Plant growth and carbon economy. In: Encyclopedia of life sciences. Nature Publishing Group. http:// www.els.net

Poorter H, Bergkotte M (1992) Chemical composition of 24 wild species differing in relative growth rate. Plant Cell Environ $15: 221-229$

Poorter H, Evans JR (1998) Photosynthetic nitrogen use efficiency of species that differ inherently in Specific Leaf Area. Oecologia 116:27-36

Poorter H, Farquhar GD (1994) Transpiration, intercellular carbon dioxide concentration and carbon-isotope discrimination of 24 wild species differing in relative growth rate. Aust J Plant Physiol 21:507-516

Poorter H, Garnier E (1999) Ecological significance of inherent variation in relative growth rate and its components. In: Pugnaire FI, Valladares F (eds) Handbook of functional plant ecology. Dekker, New York, pp 81-120

Poorter H, Pothmann P (1992) Growth and carbon economy of a fast-growing and a slow-growing grass species as dependent on ontogeny. New Phytol 120:159-166

Poorter H, Remkes C (1990) Leaf area ratio and net assimilation rate of 24 wild species differing in relative growth rate. Oecologia 83:553-559

Poorter H, Van der Werf A (1998) Is inherent variation in RGR determined by LAR at low irradiance and by NAR at high irradiance? A review of herbaceous species. In: Lambers $\mathrm{H}$, Poorter $\mathrm{H}$, van Vuuren $\mathbf{M}$ (eds) Inherent variation in plant growth, Physiological mechanisms and Ecological Consequences. Backhuys, Leiden, pp 309-336

Poorter H, Remkes C, Lambers H (1990) Carbon and nitrogen economy of 24 wild species differing in relative growth rate. Plant Physiol 94:621-627

Prioul JL, Quarrie S, Causse M, de Vienne D (1997) Dissecting complex physiological functions through the use of molecular quantitative genetics. J Exp Bot 48:1151-1163

Prioul JL, Pelleschi S, Séne M, Thévenot C, Causse M, de Vienne D, Leonardi A (1999) From QTLs for enzyme activity to candidate genes in maize. J Exp Bot 50:1281-1288

Qi X, Lindhout P (1997) Development of AFLP markers in barley. Mol Genet Genomics 254:330-336

Qi X, Stam P, Lindhout P (1998) Use of locus-specific AFLP markers to construct a high-density molecular map in barley. Theor Appl Genet 96:376-384 
Ramsay L, Macaulay M, degli Ivanissevich S, MacLean K, Cardle L, Fuller J, Edwards KJ, Tuvesson S, Morgante M, Massari A, Maestri E, Marmiroli N, Sjakste T, Ganal M, Powell W, Waugh R (2000) A simple sequence repeat-based linkage map of barley. Genetics 156:1997-2005

Reich PB, Walters MB, Ellsworth DS (1997) From tropics to tundra: global convergence in plant functioning. Proc Natl Acad Sci U S A 94:13730-13734

Reich PB, Walters MB, Tjoelker MG, Vanderklein D, Buschena C (1998) Photosynthesis and respiration rates depend on leaf and root morphology and nitrogen concentration in nine boreal tree species differing in relative growth rate. Funct Ecol 12:395-405

Robinson D, Handley LL, Scrimgeour CM, Gordon DC, Forster BP Ellis RP (2000) Using stable isotope natural abundances $\left(\delta^{15} \mathrm{~N}\right.$ and $\left.\delta^{13} \mathrm{C}\right)$ to integrate the stress responses of wild barley (Hordeum spontaneum C. Koch) genotypes. J Exp Bot 51:41-50

Rood SB, Zanewitch KP, Bray DF (1990) Growth and development of Brassica genotypes differing in endogenous gibberellin content. II. Gibberellin content, growth analysis and cell size. Physiol Plant 79:679-685

Shipley B (2002) Trade-offs between net assimilation rate and specific leaf area in determining relative growth rate: relationship with daily irradiance. Funct Ecol 16:682-689

Spoel SH, Koornneef A, Claessens SMC, Korzelius JP, van Pelt JA, Martin, Mueller J, Buchala AJ, Métraux JP, Brown R, Kazan K, van Loon LC, Dong X, Pieterse CMJ (2003) NPR1 modulates cross-talk between salicylate- and jasmonate-dependent defense pathways through a novel function in the cytosol. Plant Cell 15:760-770

Tanksley SD (1993) Mapping polygenes. Annu Rev Gen 27:205233

This D, Borries C, Souyris I, Teulat B (2000) QTL study of chlorophyll content as a genetic parameter of drought tolerance in barley. Barley Genet Newsl http://grain.jouy.inra.fr/ggpages/ bgn $/ 30 /$ dt 2 2.htm

Thomas SG, Sun T (2004) Update on gibberellin signaling. A tale of the tall and the short. Plant Physiol 135:668-676

Van der Werf A, Geerts HEM, Jacobs FHH, Korevaar H, Oomes MJM, De Visser W (1998) The importance of relative growth rate and associated traits for competition between species during vegetation succession. In: Lambers $\mathrm{H}$, Poorter $\mathrm{H}$, van
Vuuren M (eds) Inherent variation in plant growth, physiological mechanisms and ecological consequences. Backhuys, Leiden, pp 489-502

Van Ooijen JW, Maliepaard C (1996) MapQTL v. 4.0: software for the calculation of QTL positions on genetic maps. CPRO-DLO, Wageningen, The Netherlands

Van Ooijen JW, Voorrips RE (2000) Joinmap v. 3.0: software for the calculation of genetic linkage maps. Plant Research International, Wageningen, The Netherlands

Van Rijn CPE (2001) A physiological and genetic analysis of growth characteristics in Hordeum spontaneum. PhD thesis, Utrecht University

Van Rijn CPE, Heersche I, Van Berkel YEM, Nevo E, Lambers H, Poorter H (2000) Growth characteristics in Hordeum spontaneum populations from different habitats. New Phytol 146:471481

Verhoeven KJF, Vanhala TK, Biere A, Nevo E, van Damme JMM (2004) The genetic basis of adaptive population diferentiation: a QTL-analysis of fitness traits in two wild barley populations from contrasting habitats. Evolution 58:270-283

Vos P, Hogers R, Bleeker M, Reijans M, van de Lee T, Hornes M, Frijters A, Pot J, Peleman J, Kuiper M, Zabeau M (1995) AFLP: a new technique for DNA fingerprinting. Nucleic Acids Res 23:4407-4414

Wong SC, Cowan IR, Farquhar GD (1979) Stomatal conductance correlates with photosynthetic capacity. Nature 282:424-426

Wright IJ, Reich PB, Westoby M, Ackerly DD, Baruch Z, Bongers $\mathrm{F}$, Cavender-Bares J, Chapin T, Cornelissen JHC, Diemer M, Flexas J, Garnier E, Groom PK, Gulias J, Hikosaka K, Lamont BB, Lee T, Lee W, Lusk C, Midgley JJ, Navas ML, Niinemets U, Oleksyn J, Osada N, Poorter H, Poot P, Prior L, Pyankov VI, Roumet C, Thomas SC, Tjoelker MG, Veneklaas EJ, Villar $\mathrm{R}$ (2004) The worldwide leaf economics spectrum. Nature 428:821-827

Wu RL (1998) Genetic mapping of QTLs affecting tree growth and architecture in Populus: implication for ideotype breeding. Theor Appl Genet 96:447-457

Yin X, Kropff MJ, Stam P (1999) The role of ecophysiological models in QTL analysis: the example of specific leaf area in barley. Heridity 82:415-421 